\title{
Electrohydrodynamic drying: Can we scale-up the technology to make dried fruits and vegetables more nutritious and appealing?
}

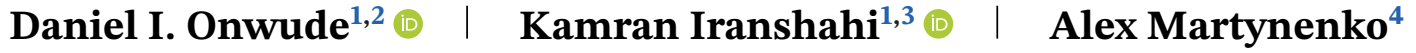 \\ Thijs Defraeye ${ }^{1,4}$ @
}

${ }^{1}$ Empa, Swiss Federal Laboratories for Materials Science and Technology, Laboratory for Biomimetic Membranes and Textiles, St. Gallen, Switzerland

${ }^{2}$ Department of Agricultural and Food Engineering, Faculty of Engineering, University of Uyo, Uyo, Nigeria

${ }^{3}$ Department of Environmental Systems Science, Swiss Federal Institute of Technology, ETH-Zurich, Zurich, Switzerland

${ }^{4}$ Department of Engineering, Dalhousie University, Faculty of Agriculture, Truro, Nova Scotia, Canada

\section{Correspondence}

Thijs Defraeye, Empa, Swiss Federal Laboratories for Materials Science and Technology, Laboratory for Biomimetic Membranes and Textiles, Lerchenfeldstrasse 5 , CH-9014 St. Gallen, Switzerland. Email: thijs.defraeye@empa.ch

\section{Funding information}

Staatssekretariat für Bildung, Forschung und Innovation, Grant/Award Number: ESKAS-2019.0643; Schweizerischer Nationalfonds zur Förderung der Wissenschaftlichen Forschung, Grant/Award Number: IZSEZ0_186498

\begin{abstract}
Electrohydrodynamic (EHD) drying is a promising technology to better preserve the nutritional content and sensory appeal of dried fruits and vegetables. To successfully scale up this technology, we need to rethink the current EHD dryer designs. There is also a significant potential to further enhance the nutritional content and sensory quality of the dried products by optimizing EHD process parameters. This study particularly highlights the current bottlenecks in scaling up the technology and improving nutrient retention and sensory appeal of the dried products. We discuss plausible future pathways to further develop the technology to produce highly nutritious dried products. Particular emphasis has been given to quantifying the residual nutritional and sensory properties of EHD dried products, and possible EHD dryer configurations for farmers and the industry. Concerning the nutritional content, EHD drying preserves vitamins, carotenes, and antioxidants significantly better than convective air drying. From the sensory perspective, EHD drying enhances the color of dried products, as well as their general appearance. With respect to scalability, placing the fruit on a grounded mesh electrode dries the fruit much faster and more uniformly than the grounded plate electrode. Future research should be directed toward simultaneous measurements of multiple food nutrients and sensory properties during EHD drying with a grounded mesh collector. Quantifying the impact of the food loading density on drying kinetics and energy consumption of the EHD drying process should also be a future research goal. Research comparing EHD drying with commercially available drying methods such as freeze-drying, microwavedrying, and infrared drying should also be carried out. This study gives promising insight toward developing a scalable novel thermal drying technology tailored to the requirements of the current and future society.
\end{abstract}

\footnotetext{
This is an open access article under the terms of the Creative Commons Attribution-NonCommercial License, which permits use, distribution and reproduction in any medium, provided the original work is properly cited and is not used for commercial purposes.

(C) 2021 The Authors. Comprehensive Reviews in Food Science and Food Safety published by Wiley Periodicals LLC on behalf of Institute of Food Technologists
} 
KEYWOR D S

convective drying, EHD drying, food quality, novel thermal drying, plant-based foods, scalability

\section{1 | INTRODUCTION}

Drying is one of the most common process technologies for preserving heat-sensitive plant-based foods such as fruits and vegetables. Drying ensures off-season availability and avoids the loss of fresh produce. Several dried fruits or vegetables contain substantial amounts of key minerals (iron, calcium (Amoasah et al., 2019; Nkumah, 2016), and are an important source of vitamins (A, E, C) (GarcíaMartínez et al., 2013; Sablani, 2006), phenolic antioxidants, and dietary fibers (Chang et al., 2016). These components are particularly essential for pregnant and breastfeeding women, elderly people and infants. Dried fruit can supplement an infant's diet already within the first year (Correia et al., 2017; Scaglioni et al., 2017) and can be locally sourced worldwide. For children, dried fruits are promoted as healthy snacks (e.g. "apple chips" or "fruit sticks/bars") or are used in cereals to increase their nutritional uptake (Johansson et al., 2010; Melanson, 2008).

Standard convective drying methods (e.g., fan-driven air drying, dehumidifier, solar drying) are being used at an industrial scale to produce these dried fruits and vegetables (Belessiotis \& Delyannis, 2011; Mujumdar, 2000; Mujumdar, 2007; Pirasteh et al., 2014; Wang, 2013). However, several of these drying methods lead to a significant loss of the aforementioned micronutrients and bioactive compounds due to a slow drying process or at elevated temperature (Mbondo et al., 2018; Moses et al., 2014). In addition to the loss of nutritional content, the sensory properties (softness, texture, color, flavor) of dried fruits and vegetables are often not that appealing to consumers, compared to other snacks. More advanced technologies, such as freezedrying, retain better nutritional content and sensory quality. However, such technologies come at a much higher energy and environmental cost and a higher product cost (Galanakis et al., 2015; Onwude et al., 2017). This drives researchers and engineers toward developing innovative and sustainable drying processes. The particular focus is on solutions that reduce the total energy consumption and carbon footprint of the drying process. At the same time, they aim to preserve the nutritional content of the fresh produce in the best way possible while ensuring optimal sensory appeal.

One such innovative drying technology is electrohydrodynamic (EHD) drying. EHD drying has recently gained significant interest as an alternative to standard convective drying. It is particularly suitable for drying heat-sensitive foods, such as fruits and vegetables (Singh et al., 2012; Defraeye \& Martynenko, 2018). This novel drying method is based on the direct use of electricity for the dewatering of wet biomaterials. A high voltage difference is invoked between emitter and collector electrodes in the kilovolt range. This difference induces electrical discharge resulting in local ionization of the air at the emitter electrode due to its large curvature (Figure 1). The ionized air is drifted toward the collector electrode by the Coulomb force. The resulting elastic and/or non-elastic collisions of the positively ionized air with neutral air particles during the air movement generate a secondary airflow, so-called ionic wind (Figure 1). Due to this ionic wind, moisture is removed convectively from a product to be dried. This technology has numerous advantages over standard convective air drying. These advantages can be categorized into those related to the drying process and those related to the resulting product quality. An advantage with respect to the drying process includes a shorter drying time when compared to hot-air and solar dryers at low or ambient temperatures (Precoppe et al., 2015; Bechoff et al., 2010; Pirnazari et al., 2014). Compared to fan-driven airflow under the same environmental conditions, drying is enhanced by enhanced convective heat and mass transfer by the ionic wind. Besides, an additional heat supply can speed up the drying mass transfer process inside the product. A further advantage is that the drying process is reported to have a lower energy consumption, so lower carbon emissions (Esehaghbeygi et al., 2014; Taghian Dinani et al., 2014a; Yang \& Ding, 2016). Other reported advantages regarding product quality include better retention of nutritional content, flavor, and color, as well as lower shrinkage and higher rehydration capacity (Bajgai et al., 2006; Defraeye \& Martynenko, 2018; Elmizadeh et al., 2017; Esehaghbeygi et al., 2014; Ni et al., 2019; Pirnazari et al., 2014).

Most studies, however, only focused on improvements in one or a few nutritional or sensory quality attributes. These studies were also performed for specific fruit and vegetable and a limited range of EHD process parameters. We currently lack a more holistic insight into the true impact of the EHD drying process on the complete set of key nutritional and sensory traits, compared to standard drying methods. In addition, the impact of the large set of EHD process parameters on these traits is still lacking. To find the optimal drying conditions, 


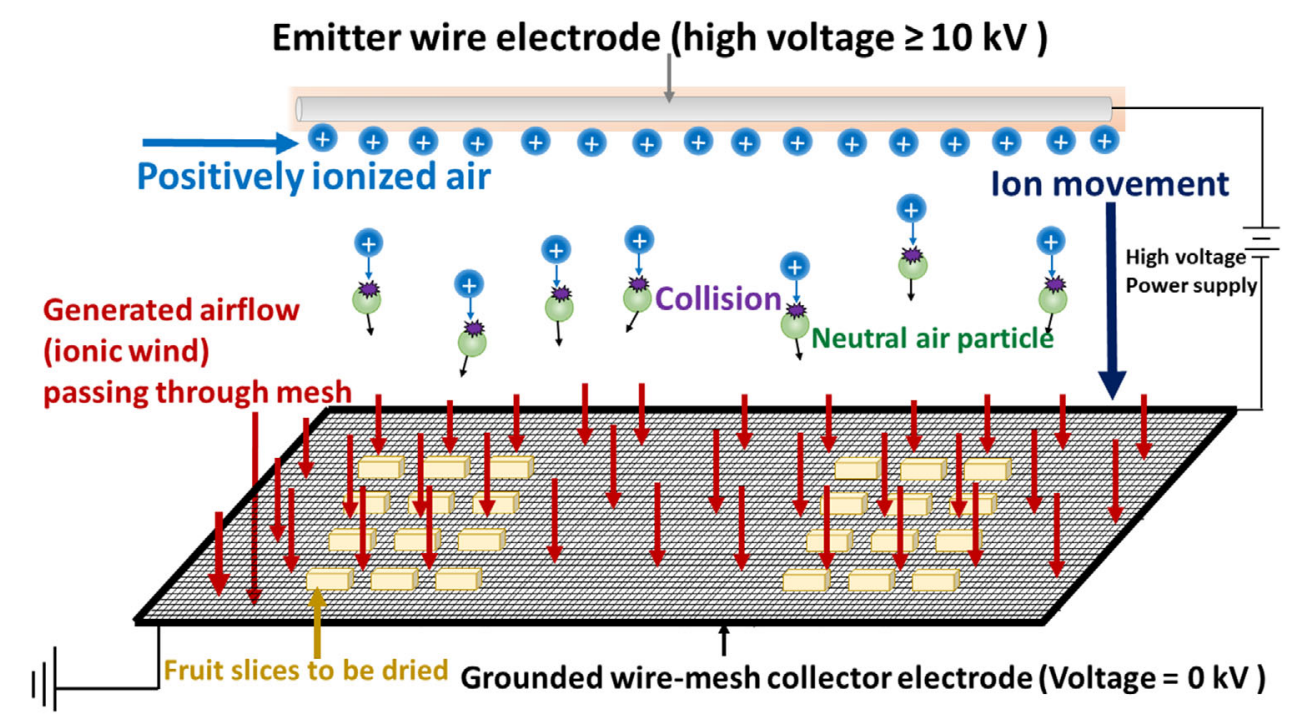

F I G U R E 1 Schematic EHD drying mechanism showing electrical discharge and interactions between positively ionized air and neutral air particles (not to scale). Note that different colored labels correspond to the different processes/phenomena/dryer components (e.g., green-colored ball shape $=$ neutral air particles)

knowledge is required across a large range of voltages, electrode geometries, electrode distances, gaps between electrodes, spacings between each product, and product thicknesses. Given the large potential of EHD drying, it is also surprising that only a few working pilot-scaled EHD drying prototypes have been successfully designed in the last two decades (Lai, 2010; Tuan et al., 2014; Liang, 2000; Liang, 2002; Takamatsu, 2012). Large EHD dryers have been locally developed for medicinal herbs drying (Martynenko \& Kudra, 2019). However, to the best of our knowledge, there is still no known industrial EHD dryer to produce dried fruits and vegetables. This raises the question of why this technology has not matured yet to industrial systems.

This paper aims to shed light on these open questions with respect to the industrial upscaling of EHD drying technology and the enhancement of nutrient retention and sensory properties. First, we quantify the added value of EHD drying of fruits and vegetables in preserving the nutritional content and sensory properties compared to convective air drying. We identify what it takes to bridge the large lacuna between current lab-scale research and future industrial scaled-up EHD drying devices. We show that future EHD dryers could be designed. We also highlight the perspectives of this for small-scale farmers and for the industry.

\section{2 | EHD DRYING MECHANISM}

EHD drying relies on airflow generation as a result of a high voltage difference between two electrodes (emitter and collector electrodes), typically in the range of 10 to $40 \mathrm{kV}$ (Singh et al., 2012) (Figure 1). The emitter is typically a set of metal wires with a diameter of several hundred micrometers or a needle with a tip radius of several hundred micrometers. The collector is a plate or metallic mesh on which the drying material is placed (Figure 1). The emitter is often connected to a positive DC high voltage power supply, while the collector is usually grounded. Due to the large curvature of the emitter (i.e., sharp edges), which results in a high local electric field strength, the air around the emitter is locally ionized. This ionized air, driven primarily by the Coulomb force, moves to the grounded collector electrode of opposite polarity in order to induce airflow, so-called ionic wind (Tadeusz Kudra \& Martynenko, 2019; Saneewong Na Ayuttaya et al., 2012). The minimum voltage required for initial corona discharge highly depends on the geometrical characteristics of the discharge and collector electrodes (curvature, emitter-collector gap, the spacing between the emitters) and the ambient conditions (humidity, temperature). Very high voltage leads to an increase in electric field strength, thereby expanding the ionization region until it reaches the grounded collector electrode. This results in spark-over or air breakdown phenomena (Martynenko \& Kudra, 2019).

When fruits are placed on a grounded collector electrode (voltage $=0 \mathrm{kV}$ ) above an emitter electrode (voltage $\geq$ $10 \mathrm{kV}$ )(Figure 1), air flow is created by ions generated in the corona discharge near the sharp electrode that drifts to the ground. As a result, the momentum of airflow is enhanced and cross flow or primary flow is generated. This generated airflow, also called ionic wind, can induce airspeeds of 0.1-10 $\mathrm{m} \mathrm{s}^{-1}$ (Alemrajabi et al., 2012; Martynenko et al., 
2017; Defraeye \& Martynenko, 2018). This "ionic wind" coupled with other mass transfer mechanisms, driven by ion flow or an electrostatic field (Martynenko et al., 2020), accelerates and alters the convective drying process. As a result, dehydrated products with different material properties and porous microstructures are created, compared to standard convective drying. A too high voltage should be avoided as this may result in noisy corona discharge or a complete breakdown of the air (Defraeye \& Martynenko, 2018).

\section{3 | PERFORMANCE INDICATORS FOR EHD DRYING}

In order to evaluate the performance of an EHD drying process and quantitatively compare it with other drying processes, the key performance indicators (KPI), as shown in Figure 2, are defined. Most of these performance indicators have been used in the past to evaluate the EHD drying of plant-based foods. They include drying rate, drying time, energy consumption, nutritional and sensory quality attributes, scalability, cost index, and greenhouse gas emissions (Bajgai et al., 2006; Dalvand et al., 2013; Ding et al., 2015; Elmizadeh et al., 2017; Esehaghbeygi et al., 2014; Fylladitakis et al., 2014; Pirnazari et al., 2016; Yang \& Ding, 2016). These KPI's are defined below.

The drying rate (DR) is defined as the amount of moisture removed from a product per unit time (Berk, 2018):

$$
D R=-\frac{d M_{w}}{M_{d} d t}=-\frac{d X}{d t} \text { with } X=\frac{M_{w}}{M_{d}}
$$

where $M_{w}$ is the mass of water in the product $(\mathrm{kg}), M_{d}$ is the mass of dry matter $(\mathrm{kg}), \mathrm{t}$ is the time (h), and $X$ is the moisture content expressed in $\mathrm{kg}$ of water per kg of dry matter.

The drying time, quantified as the critical drying time (h) is defined as the time needed for a sample to reach the critical moisture content (Defraeye \& Martynenko, 2019). Critical moisture content is defined as the averaged moisture content in the sample that corresponds to an equilibrium water activity via the sorption isotherm, below which no spoilage occurs (Defraeye \& Martynenko, 2019).

The energy consumption is quantified by means of specific energy consumption (SEC). The SEC is defined as the energy required to evaporate moisture from a product, per kilogram of water evaporated $(\mathrm{kJ} / \mathrm{kg}$ ) (Singh \& Kumar, 2013):

$$
S E C=\frac{\text { Input power } x \Delta t}{M_{w}}
$$

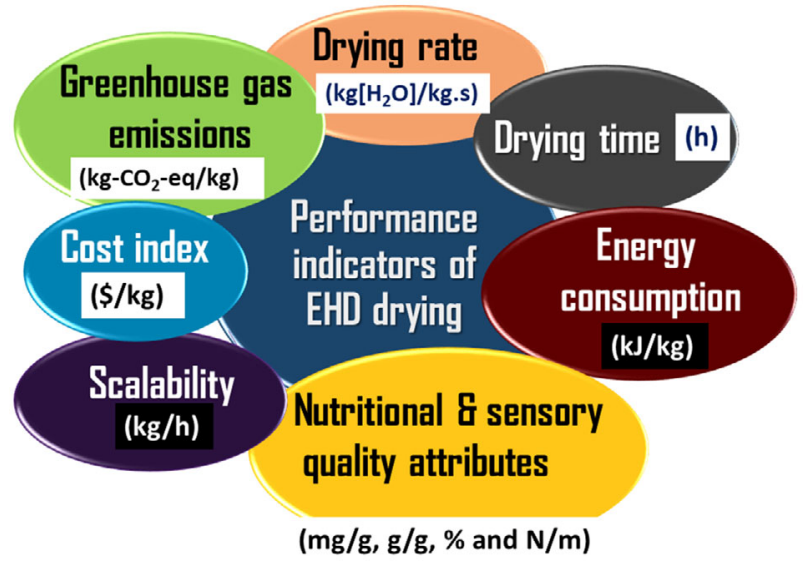

F I G U RE 2 Important performance indicators of the EHD drying process

where $\Delta t$ is the time during which the dryer is operated (h).

Metrics that quantify nutritional quality target the amount of available essential nutrients in dried food products. These nutrients are, for example, vitamins $(\mathrm{mg} / \mathrm{g}$ of fresh weight), carotenes ( $\mathrm{mg} / \mathrm{g}$ dry weight), flavonoids (mg/100 g dry weight), polysaccharide ( $\mathrm{g} / 100 \mathrm{~g}$ dry weight) and polyphenols (mg/100 g dry weight) (Bualuang et al., 2017; Ni et al., 2019; Sarker et al., 2020; Zhao et al., 2014). On the other hand, sensory quality implies the organoleptic properties of dried food. The sensory traits are detectable by human senses and determine the acceptability by consumers of the particular product. The sensory qualities include color (lightness:0-100, redness or greenness: -60 to +60 , and yellowness or blueness: -60 to +60 ), taste (\%-score), hardness ( $\mathrm{N} / \mathrm{m})$, appearance (\%-score), and odor (\%-score) (Antonio-Gutiérrez et al., 2019; Sharma \& Prasad, 2001; Tan et al., 2009).

The scalability is the ability to dry large amounts of foods with similar efficiency as smaller amounts of products. Scalability of a dryer is quantified as the amount of dried product in the dryer divided by the total drying time of the products $(\mathrm{Kg} / \mathrm{h})($ Kasper et al., 2014):

$$
\text { Scalability }=\frac{M_{d}}{\text { drying time }}
$$

The cost index $(C I)$ is a metric indicative of costeffectiveness. The $\mathrm{CI}$ is defined as the total cost incurred in producing a specific quantity of dried product, to the amount of dried product ( $\$ / \mathrm{kg}$ of dried products) (Tippayawong et al., 2008):

$$
C_{I}=\frac{C}{M_{d}}
$$

where $C$ is the total cost of production (\$) 
Greenhouse gas emissions (GHGE) are used to determine the environmental impact of the production process. It is defined as the measured amount of equivalent $\mathrm{CO}_{2}$ emission per unit mass of the dried product $\left(\mathrm{kg}-\mathrm{CO}_{2}-\right.$ equivalent $/ \mathrm{kg}$-dry product) (Tippayawong et al., 2008):

$$
\mathrm{GHGE}=\frac{M_{\mathrm{co}_{2-e q}}}{M_{d}}
$$

where $M_{c o_{2-e q}}$ is the mass of equivalent $\mathrm{CO}_{2}(\mathrm{~kg})$

\section{4 | NUTRIENT RETENTION AND SENSORY QUALITY OF FRUITS AND VEGETABLES AS AFFECTED BY EHD DRYING}

There has been an increasing demand for dried fruits and vegetables as healthy snacks in the food industry because of their health benefits (Dominick et al., 2018; Rana \& Paul, 2017; Vukasovič, 2016). However, we are currently facing the problem of the availability of commercial dryers that can enhance the nutrients and sensory quality of dried fruits and vegetables.

\section{1 | Why should we retain the nutritional and sensory quality of dried fruits and vegetables?}

Fruits and vegetables are rich sources of vitamins (A, B, $\mathrm{C}$, and $\mathrm{E}$ groups), minerals (especially electrolytes and trace elements), and phytochemicals, especially antioxidants (Slavin \& Lloyd Beate, 2012). These compounds provide an array of important functions in the body. For instance, vitamin A is important for growth and development, enhancing the body's immune system against diseases and maintaining good vision (Codex Alimentarius Commission, 2017). Electrolytes such as potassium help reduce high blood pressure, protect against stroke, and promote proper muscle functioning in humans. Selenium, a trace element, is essential for human reproduction, DNA synthesis, hormone metabolism, and protection against infections (Filippini et al., 2017). B-vitamins are important in converting food into energy (Titcomb \& Tanumihardjo, 2019). Other micronutrients in fruits and vegetables, such as vitamins $\mathrm{C}$ and $\mathrm{E}$, serve as powerful antioxidants to protect cells from cancer-causing agents (Kong \& Chandel, 2020).

A lot of people in low- and middle-income countries have a deficiency in these essential compounds. For example, a report from the Chinese Academy of Agricultural Sciences indicated that in China, the average person obtains less than $0.06 \mathrm{mg}$ of selenium (Se) per day (Huang \& Zhang, 2012). About $72 \%$ of the studied persons were found to be selenium deficient. In India, children from low-income families consumed as little as $8.2 \mathrm{mg}$ of vitamin C per day, which is only $20 \%$ of the recommended daily intake (FAO/WHO Expert Consultation, 2005). Other studies that were done in China and Gambia also found the daily intake of vitamin $\mathrm{C}$ in the diet of adolescents to be lower than the recommended (FAO/WHO Expert Consultation, 2005). These nutritional deficits could be alleviated by enhancing the nutritional composition of processed food that, at the same time, satisfies the subjective sensory perception of customers. Increasing the quality of the consumers, especially children's diet in this way, will help improve health and reduce their predisposition to infectious diseases. Dried fruits and vegetables could help serve this purpose. The main reason is that the raw material is produced worldwide, and the dried products can be preserved much longer, guaranteeing year-round access to nutrients. However, a lot of these heat-sensitive compounds are destroyed during drying either due to temperature effect or slow drying process. Often, the destruction of these compounds is much larger than the differences in the final quality of products dried using different drying methods or processing parameters. Since the nutritional content of these processed foods is often quite low, the potential of dried fruits to enrich the consumers' daily diet is still rather limited.

\section{2 | How can we better preserve the quality of dried fruits and vegetables using EHD drying?}

The impact of several standard drying methods on the nutritional composition and sensory properties of dried fruits and vegetables has been discussed extensively (Jayaraman \& Das Gupta, 2014). Hot-air, low-humidity air freezing, infrared drying, microwave, and microwaveconvective drying methods have all been used to preserve the vitamins, polyphenols, carotenoids, $\beta$-carotene, ascorbic acid, minerals, and color quality of various dried fruits and vegetables (Madhava Naidu et al., 2016; Asami et al., 2003; İncedayi et al., 2016; Izli et al., 2014). However, most of these drying methods (e.g., hot-air) still destroy a large part of the nutrients in dried fruits and vegetables due to elevated temperatures or slow drying process (Huang \& Zhang, 2012).

EHD drying provides a good alternative to the currently used conventional drying methods for fruits and vegetables (Table 1). This novel drying technology has a unique drying mechanism (see section 2) that results in a low product temperature, coupled with high convective airflow, so 

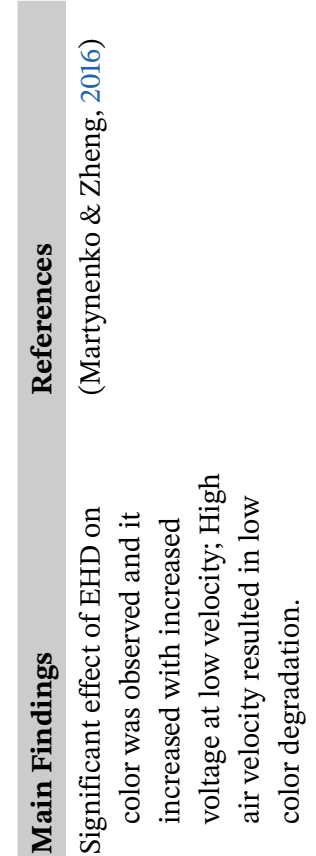
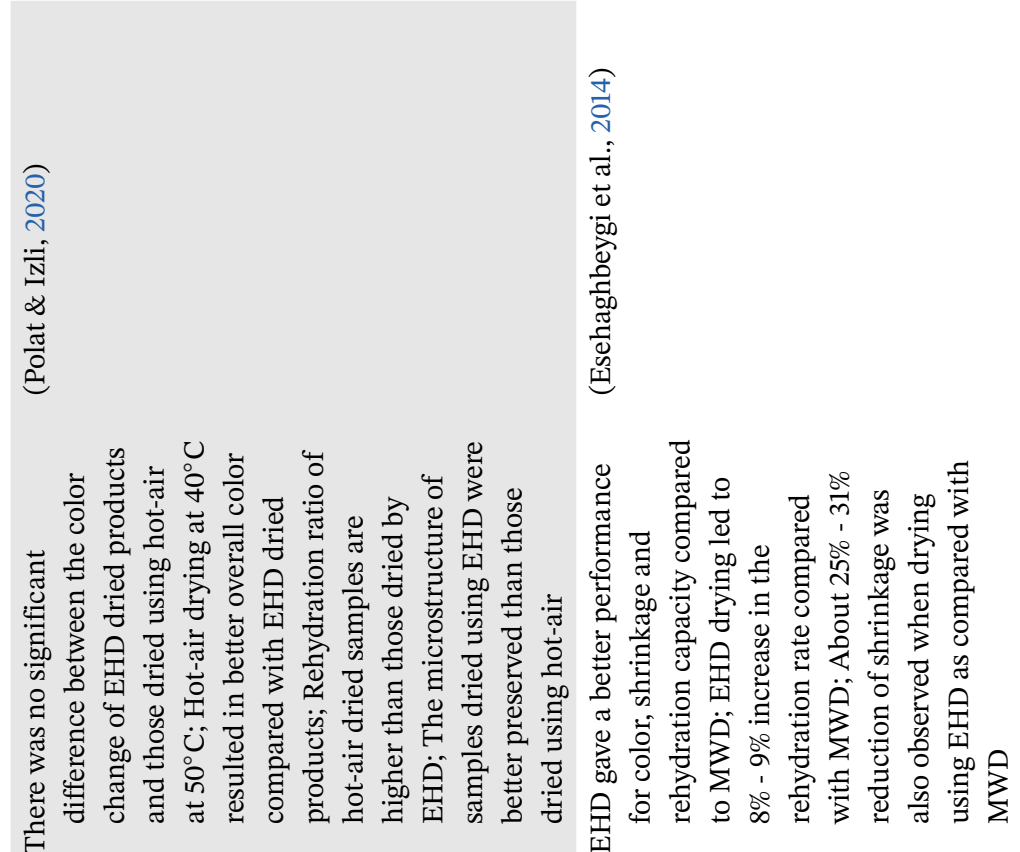
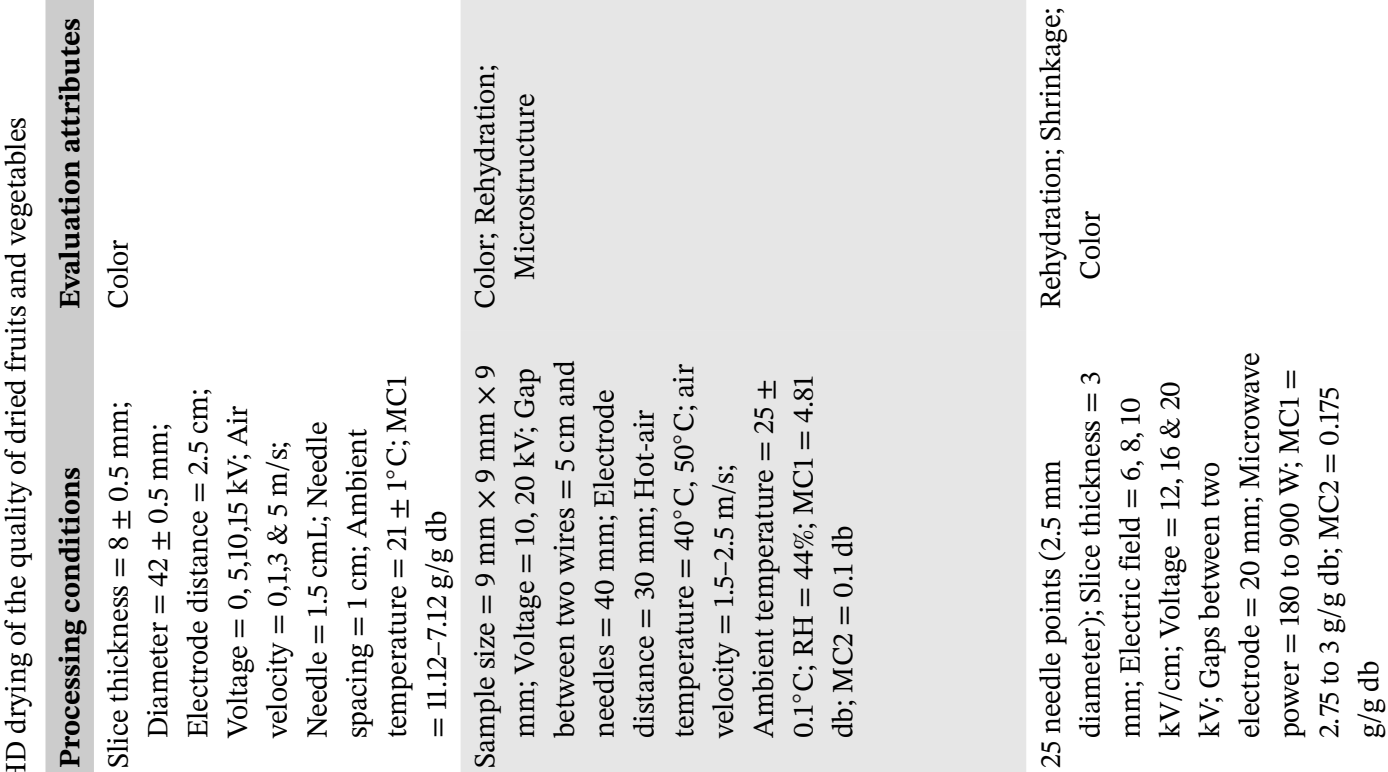

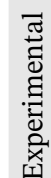

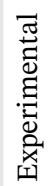
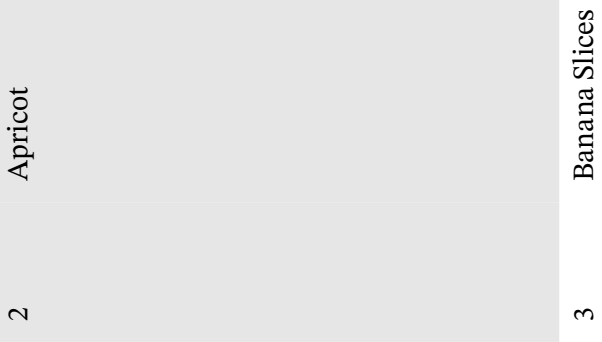

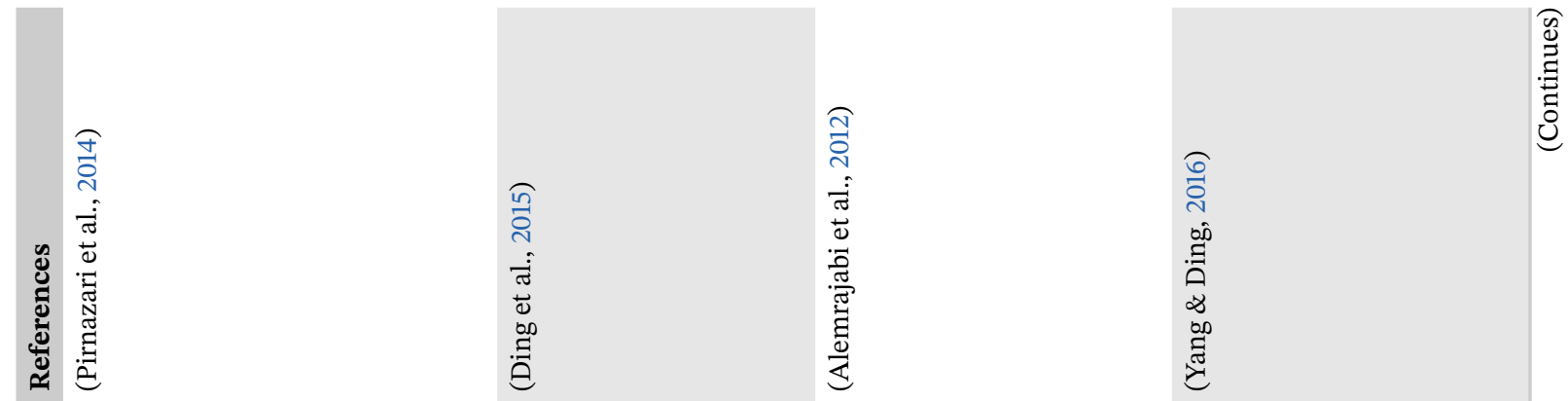

逽焉

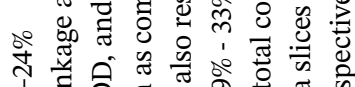
宊

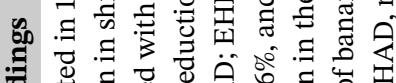

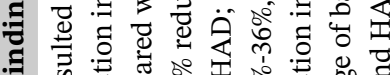

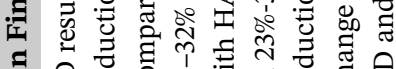

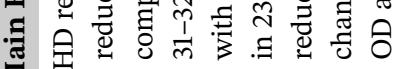
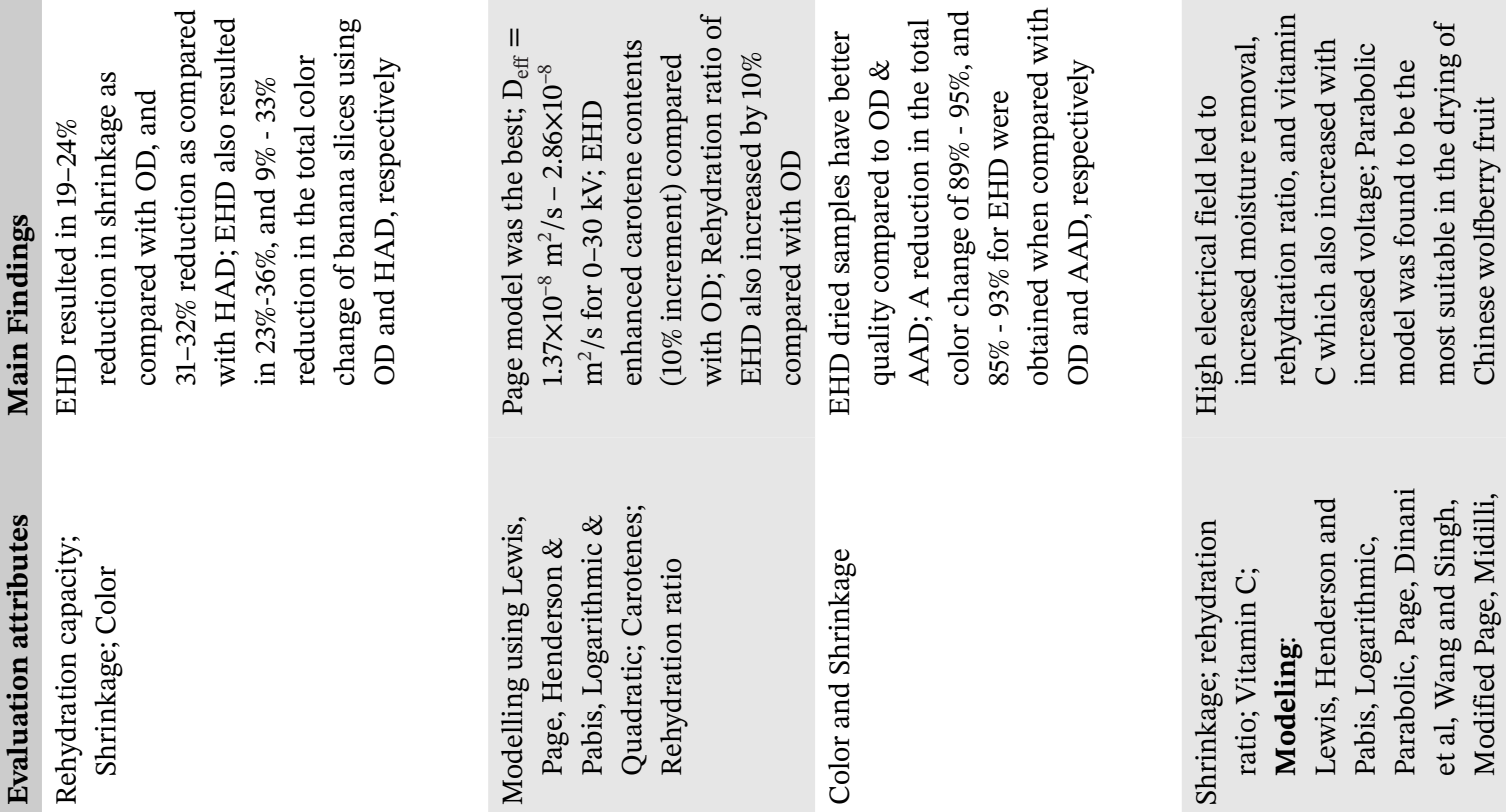

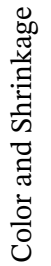

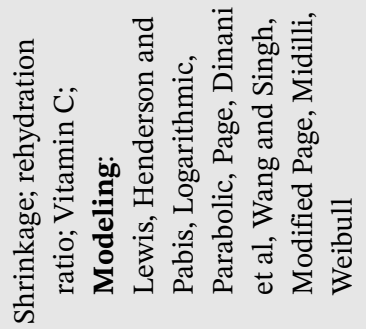

n $\quad$ घี

a $\infty$ 品

实

:

¿ II

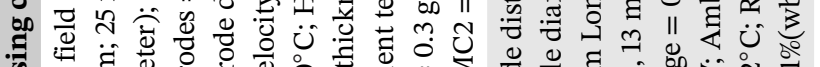

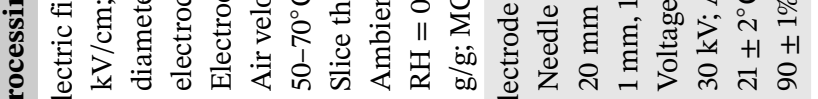

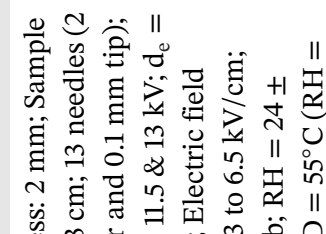

घे

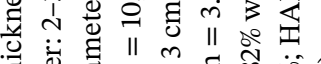

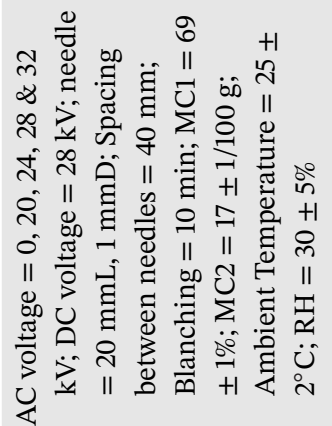

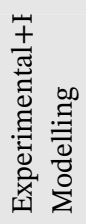

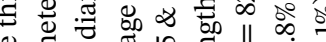

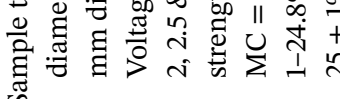

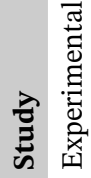

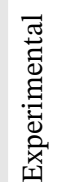
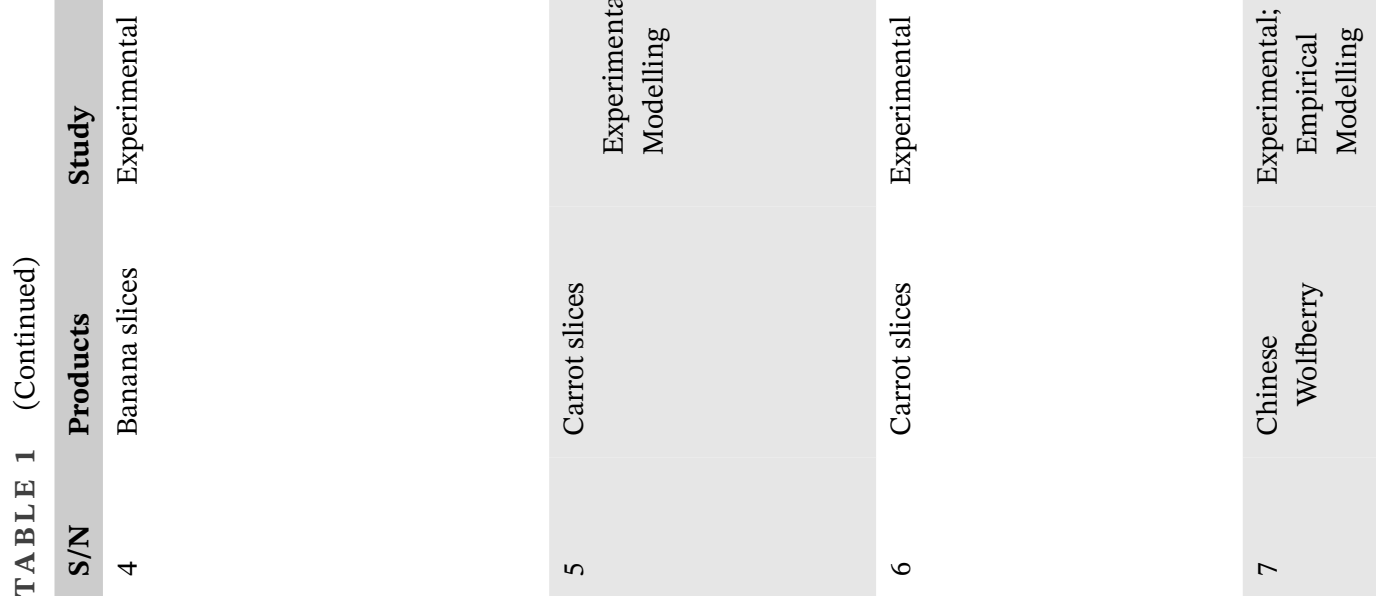
$5290 \quad$ Comprehensive

FORTIFYING THE QUALITY OF DRIED FRUITS VIA SCALABLE ELECTROHYDRODYNAMIC DRYING

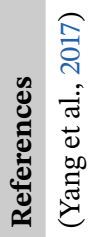

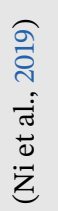

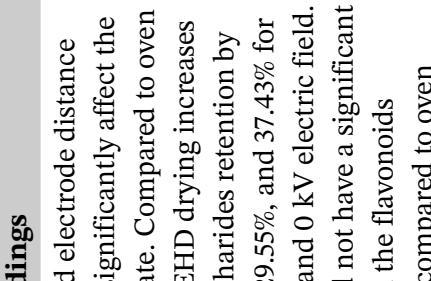

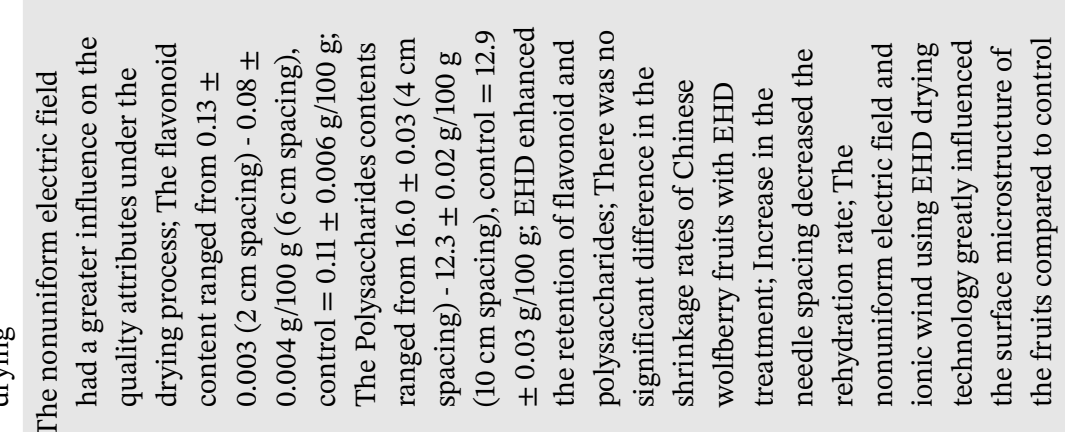

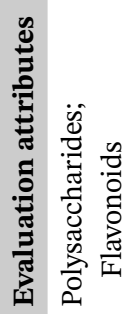

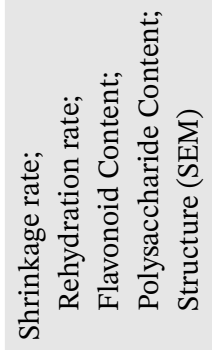

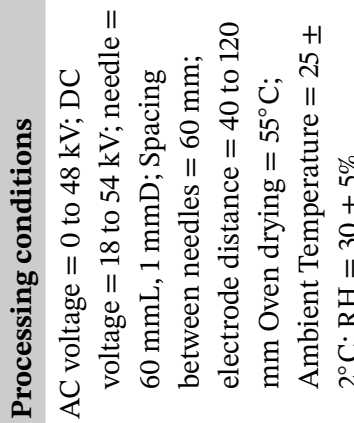

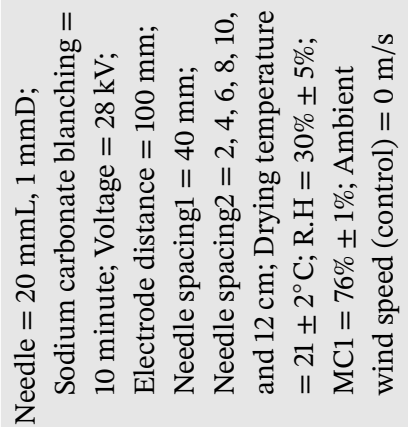

焉
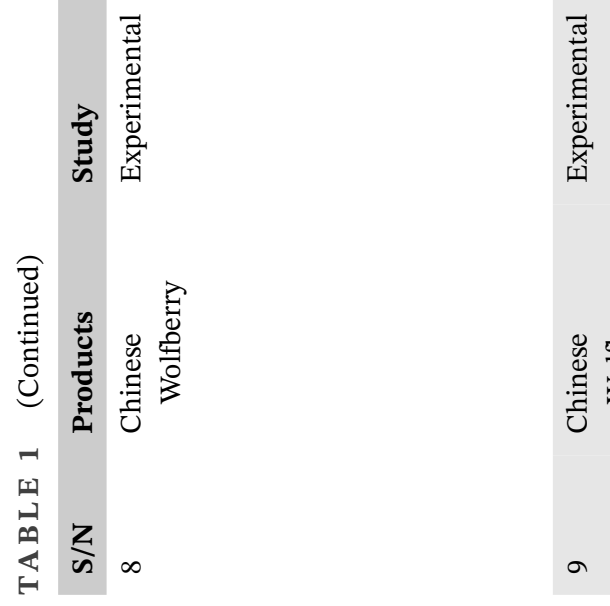

高高 

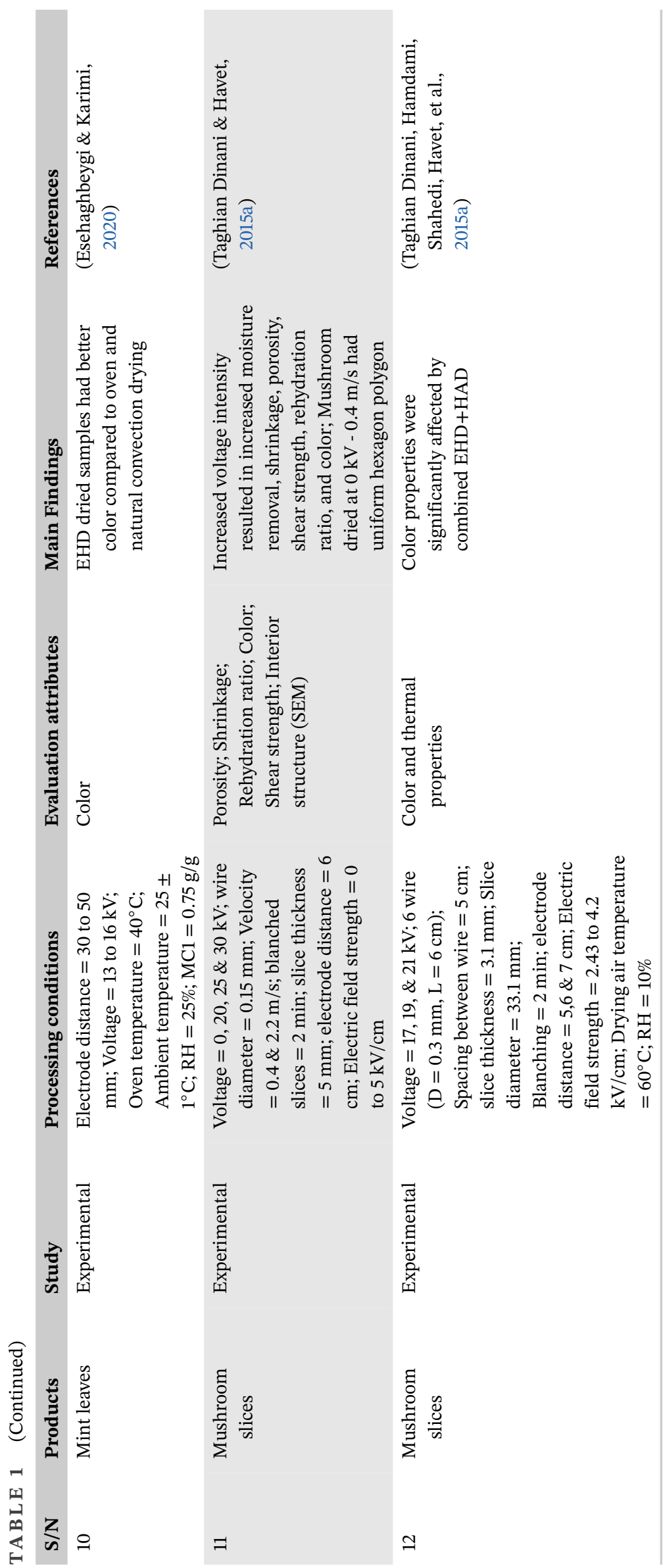

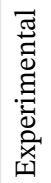
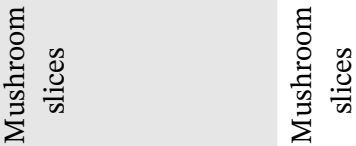

$\simeq$ 

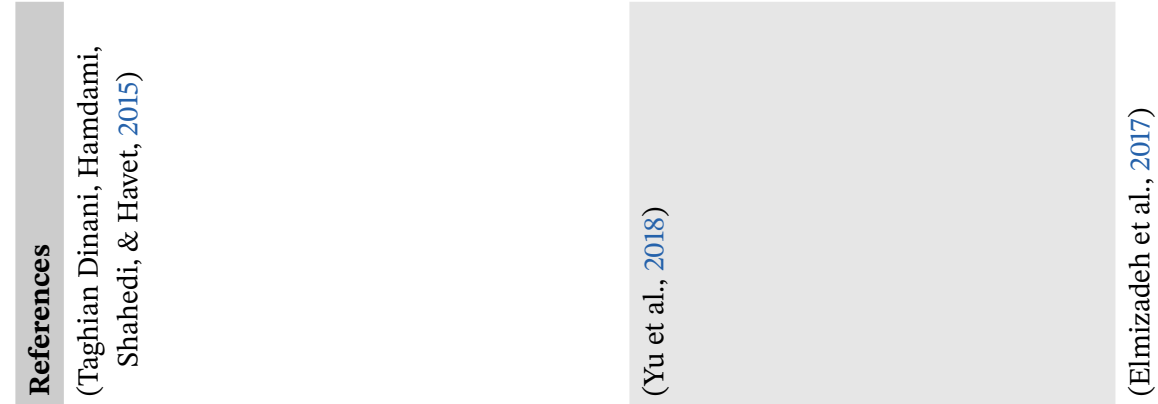

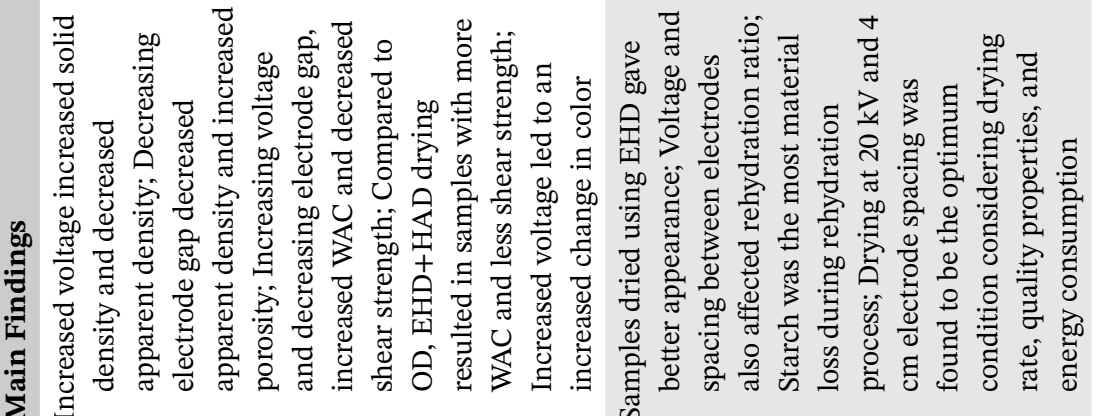

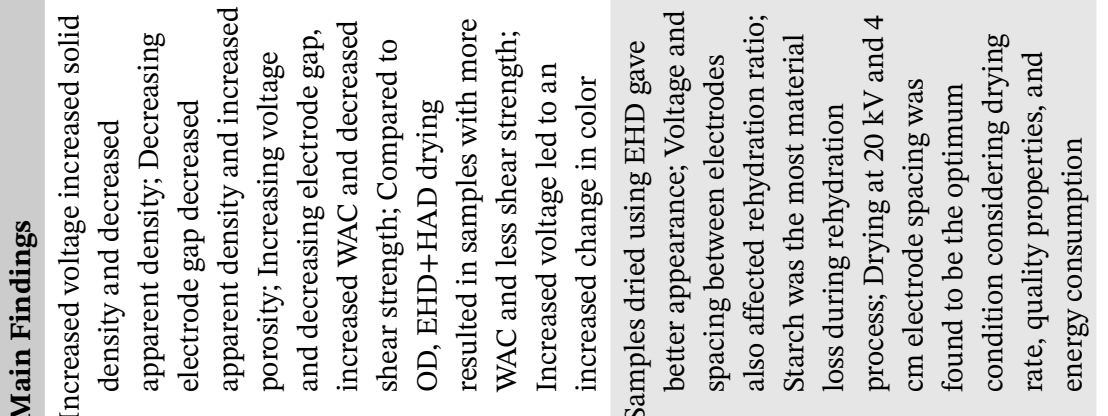

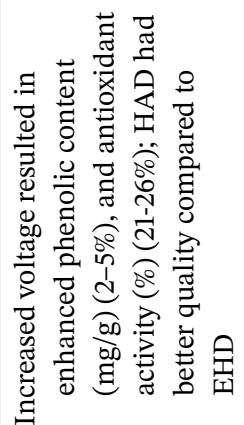

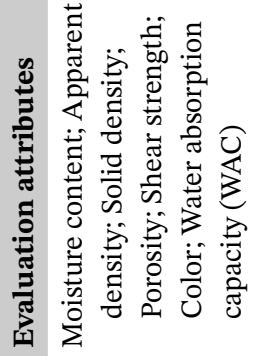

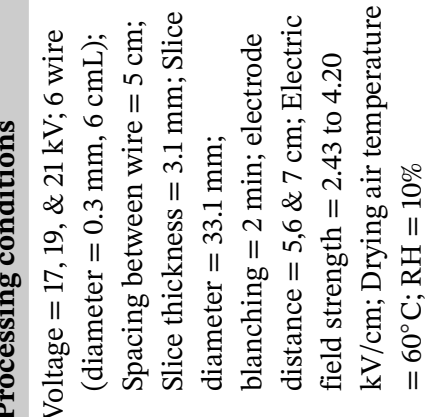

窇苛

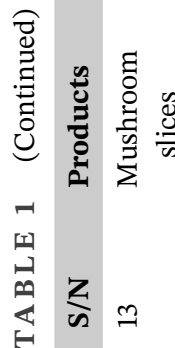

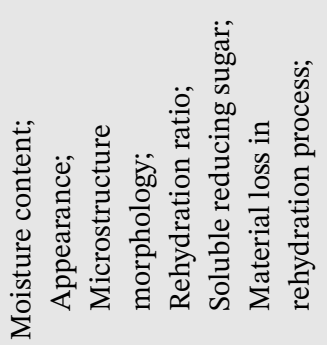

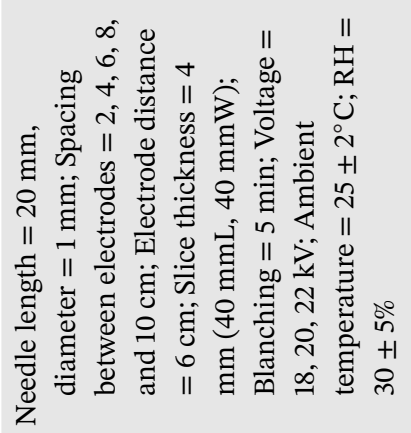

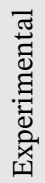

0
0
0
0
0
0
0

$\exists$

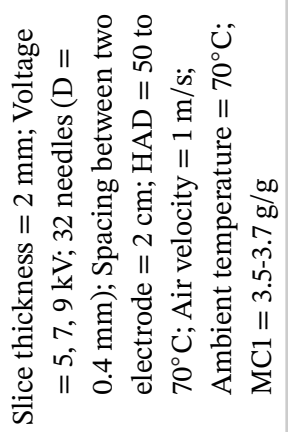

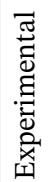

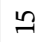

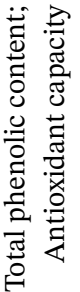

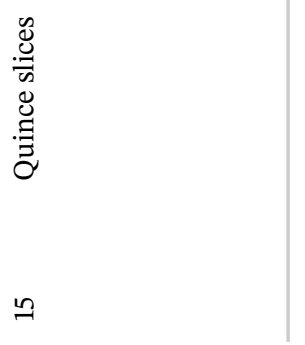



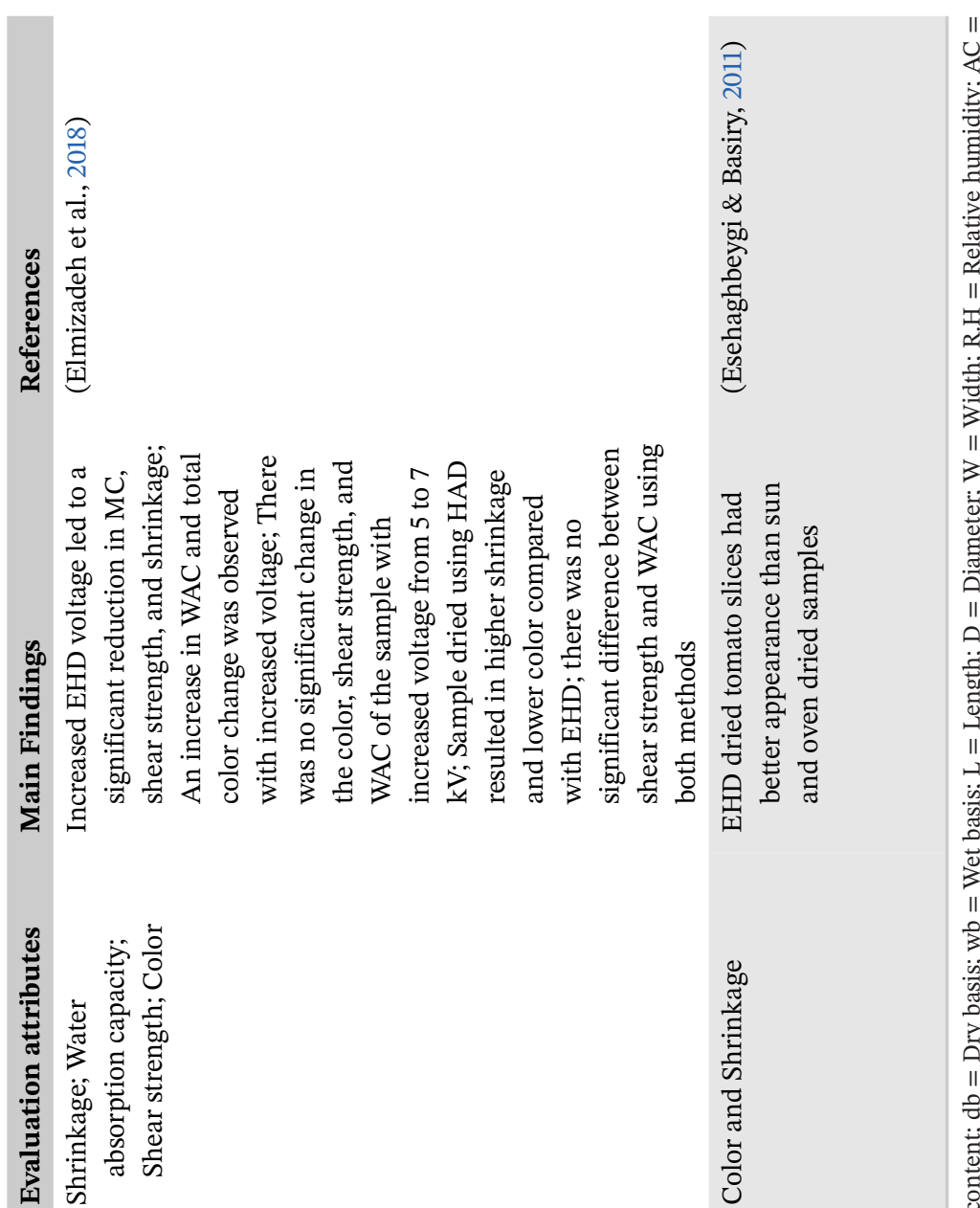

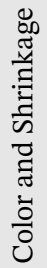
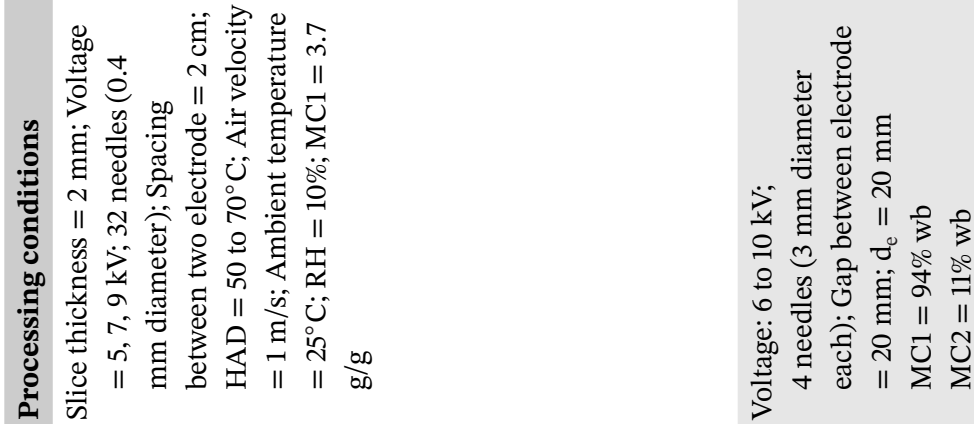

总蓠

퓰
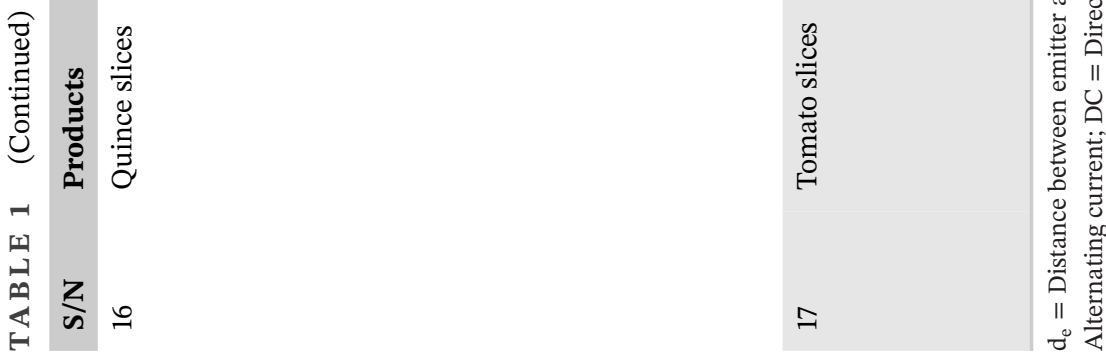


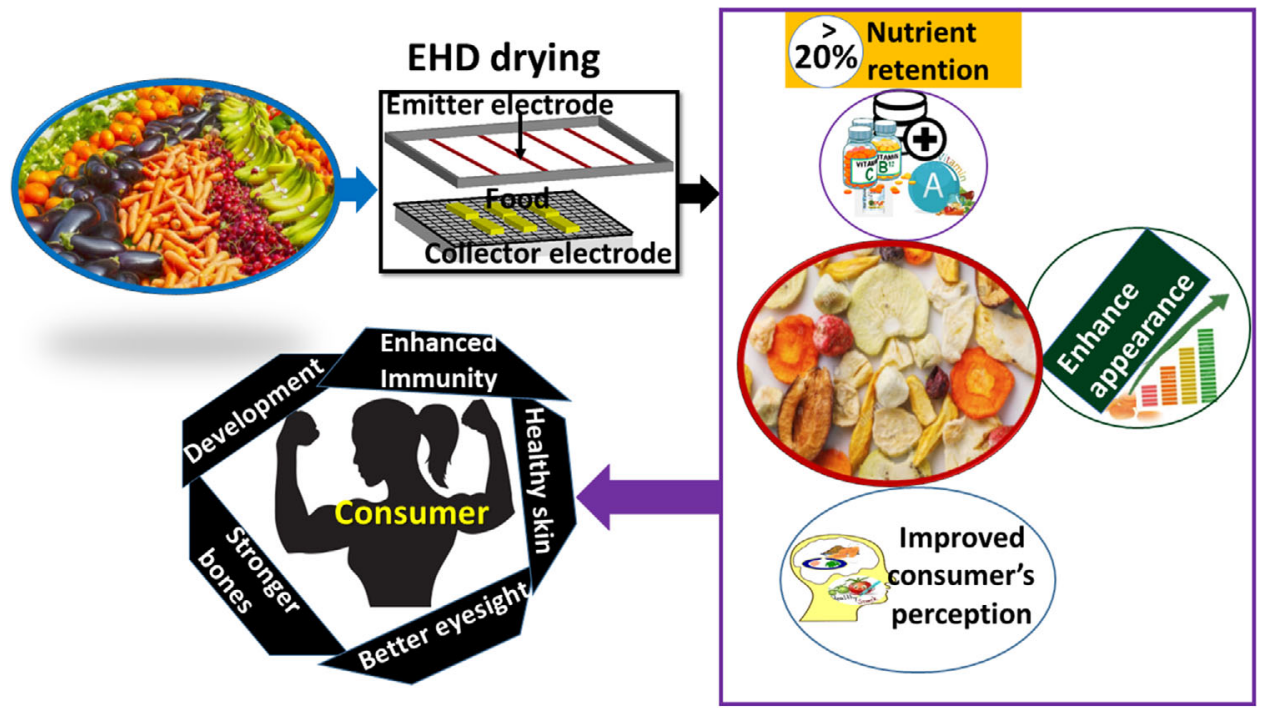

F I G U R E 3 A typical representation of the impact of EHD drying process on the quality of fruits and vegetables

a fast drying process. Due to these unique attributes of EHD drying, dried fruits and vegetables of higher nutritional density and enhanced sensory quality can be produced compared to convective air drying.

\subsection{How does EHD affect the quality of dried fruits and vegetables?}

\subsection{1 | Nutritional composition}

Table 1 summarizes selected EHD drying studies on the nutritional content and sensory quality of dried fruits and vegetables within the past decade. From Table 1, we analyzed how EHD process parameters impact the nutritional quality attributes of fruits and vegetables. Only two process parameters, namely voltage and gap between electrodes, are correlated to a few nutritional quality attributes (carotene, vitamin C, flavonoid, and polysaccharides) (Ding et al., 2015; Yang \& Ding, 2016; Yang et al., 2017; $\mathrm{Ni}$ et al., 2019; Elmizadeh et al., 2017). Very few studies quantified the nutrient retention of EHD dried fruits and vegetables, and compared them to oven drying, ambient air drying, hot-air drying, and microwave drying (Ding et al., 2015;Yang \& Ding, 2016; Yang et al., 2017; Ni et al., 2019; Elmizadeh et al., 2017). Studies compared with other highend standard industrial drying methods, including freezedrying, dehumidifier, and vacuum drying, are unknown. EHD drying was found to preserve carotene in dried carrots better (10\% increment) than oven drying, but not so much for preserving the phenolic compounds in quinces (Table 1). Polysaccharides in Chinese wolfberry were better retained by about $48 \%$ with EHD drying compared to oven drying (Table 1). The retention of vitamin C (25\%) and flavonoid (18\%) in the Chinese wolfberry were also enhanced by EHD drying compared to ambient air drying (Table 1). Figure 3 shows a typical framework of the impact of EHD drying on the nutritional composition and sensory quality of dried fruits and vegetables.

The above analysis shows that the voltage and the gap between electrodes directly affect the ability of EHD dried fruits and vegetables to better retain nutrients (Table 1). Since only voltage and gaps between electrodes were considered (Table 1), it becomes very difficult to generalize the effects of EHD process parameters on the nutritional composition. Besides, very few nutritional quality attributes have been quantified in a limited number of studies. Therefore, we need more insight into the extent to which the multiple nutrients are preserved better (e.g., vitamins, minerals, phytochemicals). Moreso on how they are affected by multiple process parameters (e.g., voltage, the gap between electrodes) as compared with standard drying methods for adequate process optimization. Also, more insight into the extent EHD drying and standard convective air drying reduces the residual nutrients of dried fruits and vegetables, compared to fresh produce is required. In any case, it is worthy to note that the changes in the nutritional content of dried products due to changes in process parameters or drying methods do not out-weight the loss in the nutrient as a result of the drying process.

\subsection{2 | Sensory properties}

From Table 1, the impact of three EHD process variables on the sensory properties was explored. These are 
voltage, the gap between electrodes, and electrode distance. The following sensory properties were measured in multiple studies, however not all together: color, appearance, rehydration ratio, shrinkage, water absorption capacity, and shear strength. It was found that EHD drying resulted in reduced color degradation (9-36\% reduction) of apples (Martynenko \& Zheng, 2016), banana (Esehaghbeygi et al., 2014; Pirnazari et al., 2014), carrot (Alemrajabi et al., 2012), and tomato slices (Esehaghbeygi \& Basiry, 2011) as compared to standard convective drying methods. EHD also provides superior appearance, flavor, less hardness, less shrinkage ( $25 \%$ - $32 \%$ reduction), and better rehydration capacity ( $8 \%$ - $9 \%$ increase) of food compared to conventional air-drying methods (Esehaghbeygi \& Basiry, 2011; Elmizadeh et al., 2018; Yu et al., 2018; Taghian Dinani et al., 2015; Taghian Dinani \& Havet, 2015a; Ni et al., 2019; Yang \& Ding, 2016; Alemrajabi et al., 2012; Pirnazari et al., 2014; Esehaghbeygi et al., 2014). Researchers also explored the use of EHD drying combined with convective airdrying (cross-flow) to enhance the color and textural quality attributes of dried fruits and vegetables (Table 1). However, its comparative advantage over EHD drying alone has not been properly elucidated. A few studies conducted blanching as a pretreatment prior to EHD drying to reduce the enzymatic reaction and improve the structural properties of dried fruits and vegetables (Taghian Dinani, Hamdami, et al., 2014). However, the effect of blanching on different sensory properties of dried fruits and vegetables was not quantified.

From this analysis (Table 1), we see that voltage and electric field strength play a significant role in enhancing the color, rehydration capacity, shrinkage, density, porosity, and shear strength of dried fruits and vegetables. But not so much for the visual appearance. The electrode distance directly affects the improvement of color, apparent density, porosity, shear strength, and WAC of dried products. The gap between the electrodes is also significant in enhancing the color and rehydration capacity of dried fruits and vegetables. The analysis also showed that most studies focused on the effect of a few processing parameters on a few sensory properties of dried fruits and vegetables. As such, future studies should quantify the impact of multiple EHD drying variables on multiple sensory properties.

\section{5 | EHD DRYING SCALABILITY}

To examine the potential of scaling EHD to dry a large amount of food faster and more uniformly, a brief insight into several EHD dryer configurations is required. For this reason, we identified and analyzed the most relevant EHD design configurations for the drying of fruits and vegetables based on literature during the past decade.

\section{1 | How can we scale-up EHD drying technology?}

Table 2 highlights selected literature on EHD drying of fruits and vegetables using different electrode design configurations. In addition, several EHD design configurations are depicted in Figure 4. Some of these have been evaluated already in several studies and others have been proposed by the authors.

\subsection{1 | What are the commonly used EHD dryer design configurations?}

From Table 2, the commonly used EHD dryer design configurations are the multiple needle-to-plate (Figure 4a), single wire-to-plate (Figure 4b), and multiple wire-to-plate (Figure 4c). These design configurations have been used to dry several fruits and vegetables such as tomato, carrot, kiwi fruit, banana, Chinese wolfberry, mushroom, apple, quince, mango, and potato using lab-scale setups (Table 2). Most EHD studies using these configurations were limited to a small number of fruits and vegetables and not in commercial quantities. The process variables of voltage, electrode distance, the gap between electrode and airspeed were correlated to the drying rate, energy efficiency, and final product quality (Table 2). The impact of other parameters on the EHD drying process was not reported. These parameters include the shape and thickness of the food, and the size and geometry of the collector electrode. Others are the number of products placed on the collector electrode (loading density) and spacing between products (for multiple products).

\subsubsection{What are the hurdles in upscaling the commonly used EHD design configurations?}

There is a growing interest in developing EHD drying technology for drying commercial quantities of fruits and vegetables. However, as is often the case with most novel food processing techniques, upscaling EHD drying to industrial systems has been difficult. One hurdle is that most laboratory-scale EHD dryers have used a plate collector electrode on which the fruits are placed (Defraeye \& Martynenko, 2018). It is difficult to achieve a uniform drying rate for multiple food products using these plate collector configurations (Defraeye \& Martynenko, 2019). When drying with a single wire, the EHD generated air-jets moves 


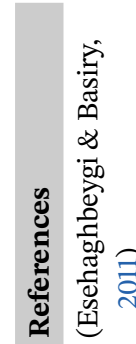

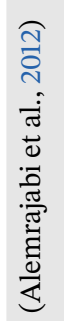

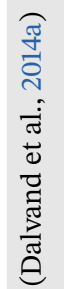

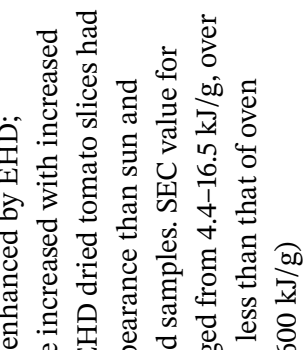

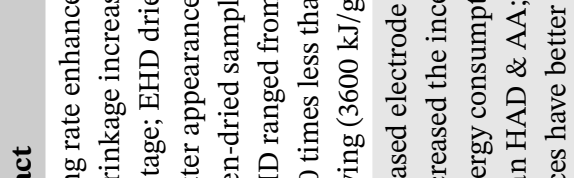

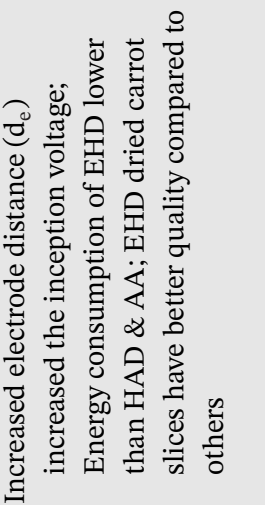

Е

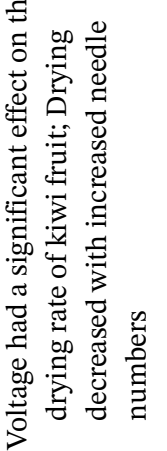

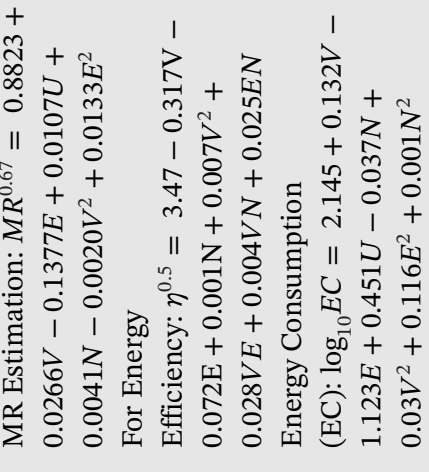

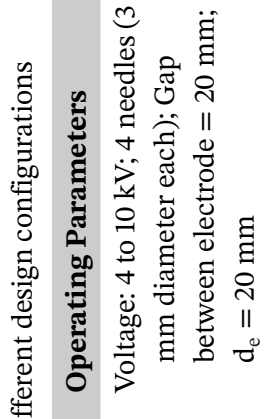

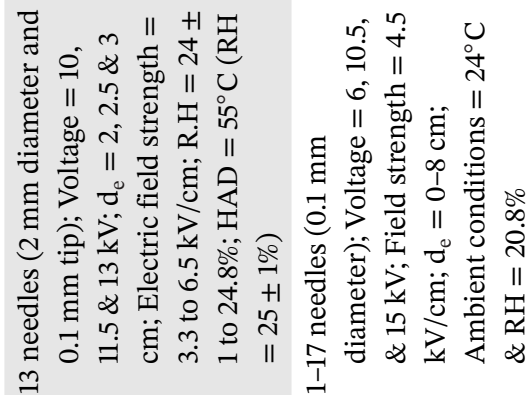

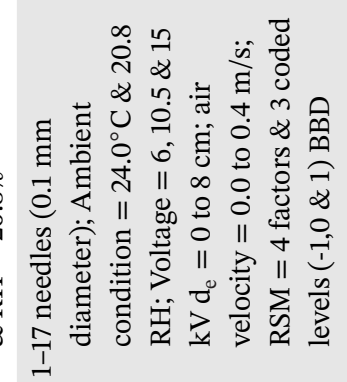

$\stackrel{6}{\Xi}$
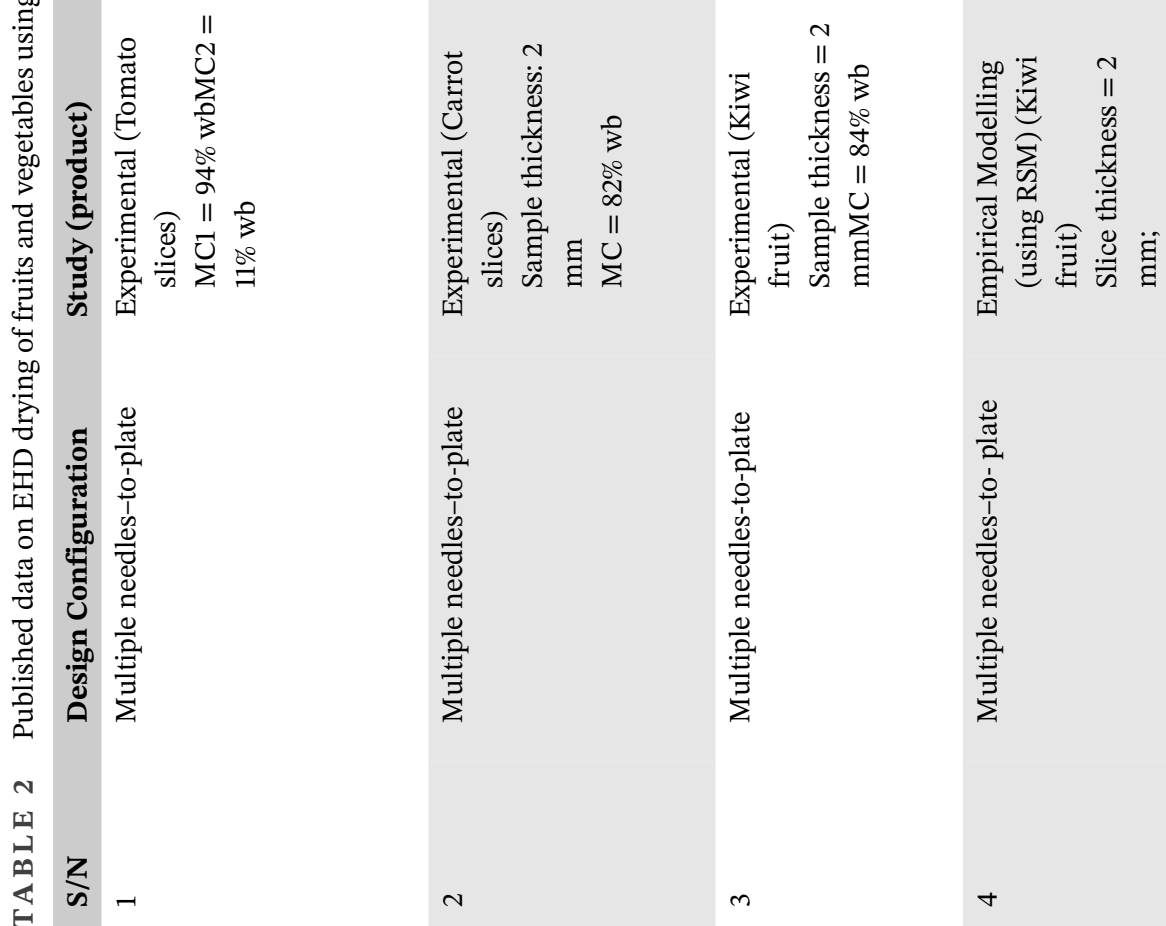

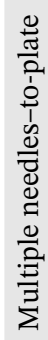

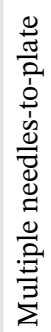

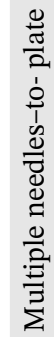




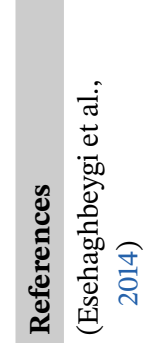

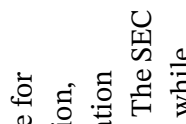

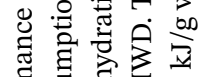
署

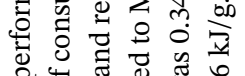
ڤై

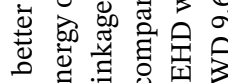
政

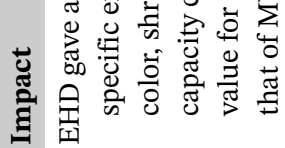

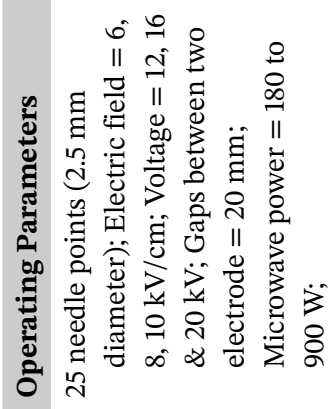

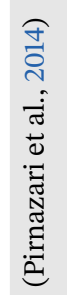

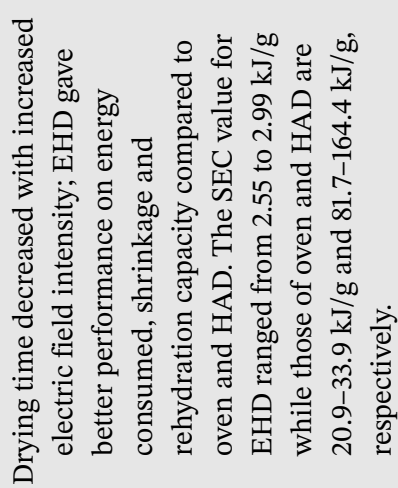

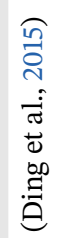
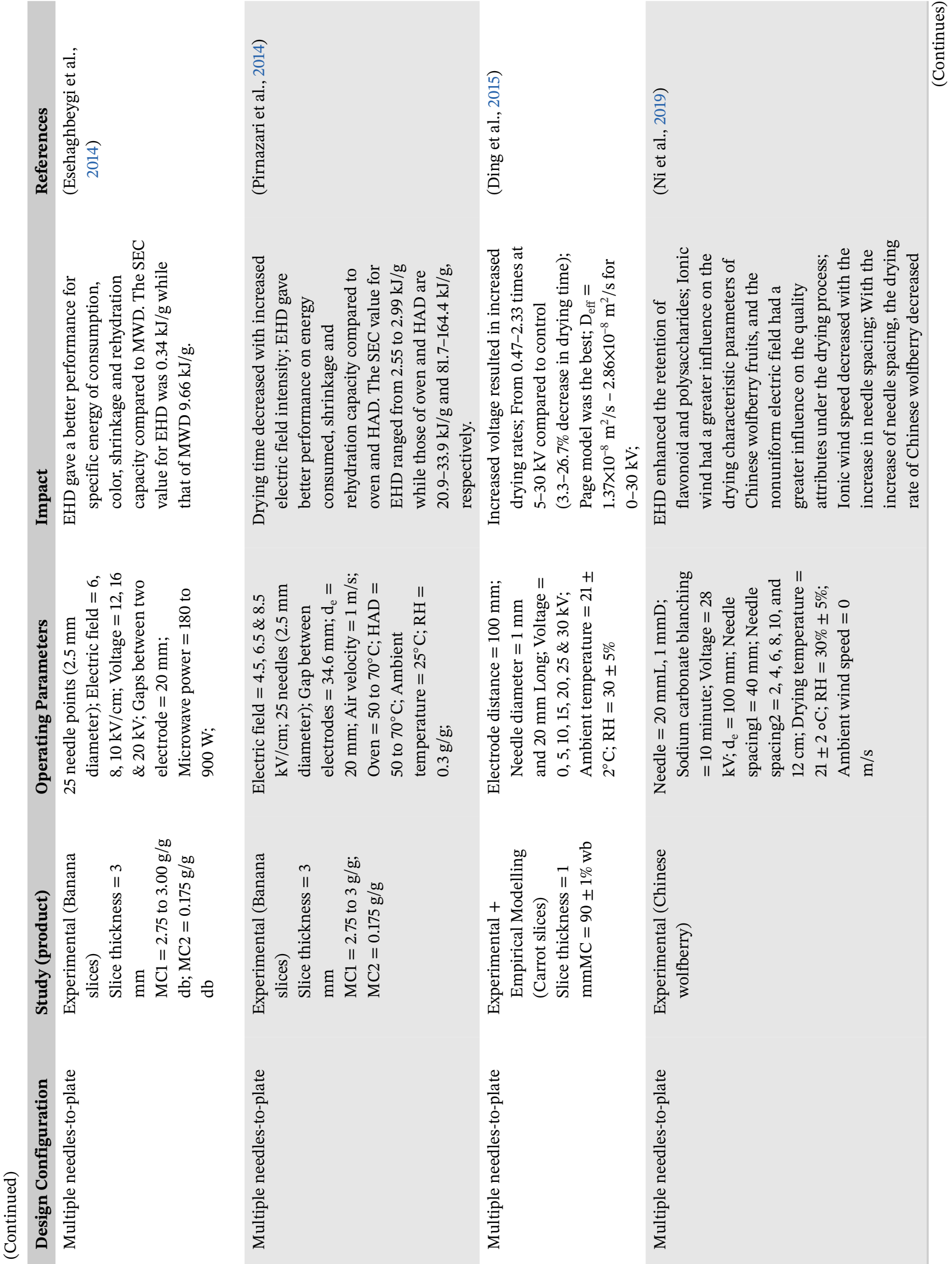

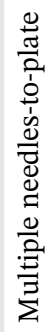

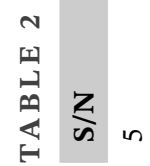

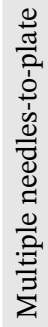

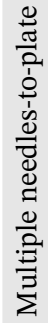

$\infty$ 

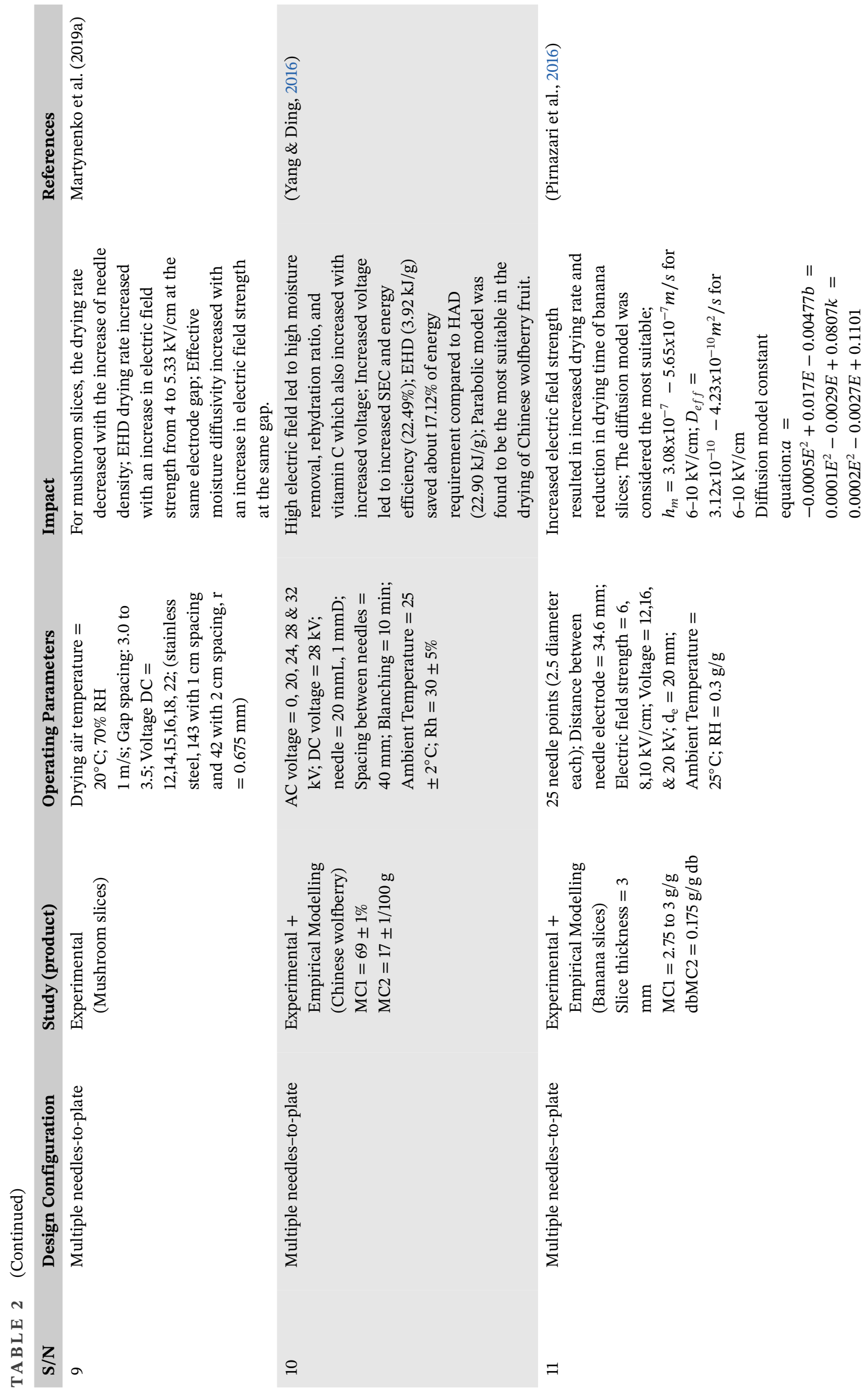

오 

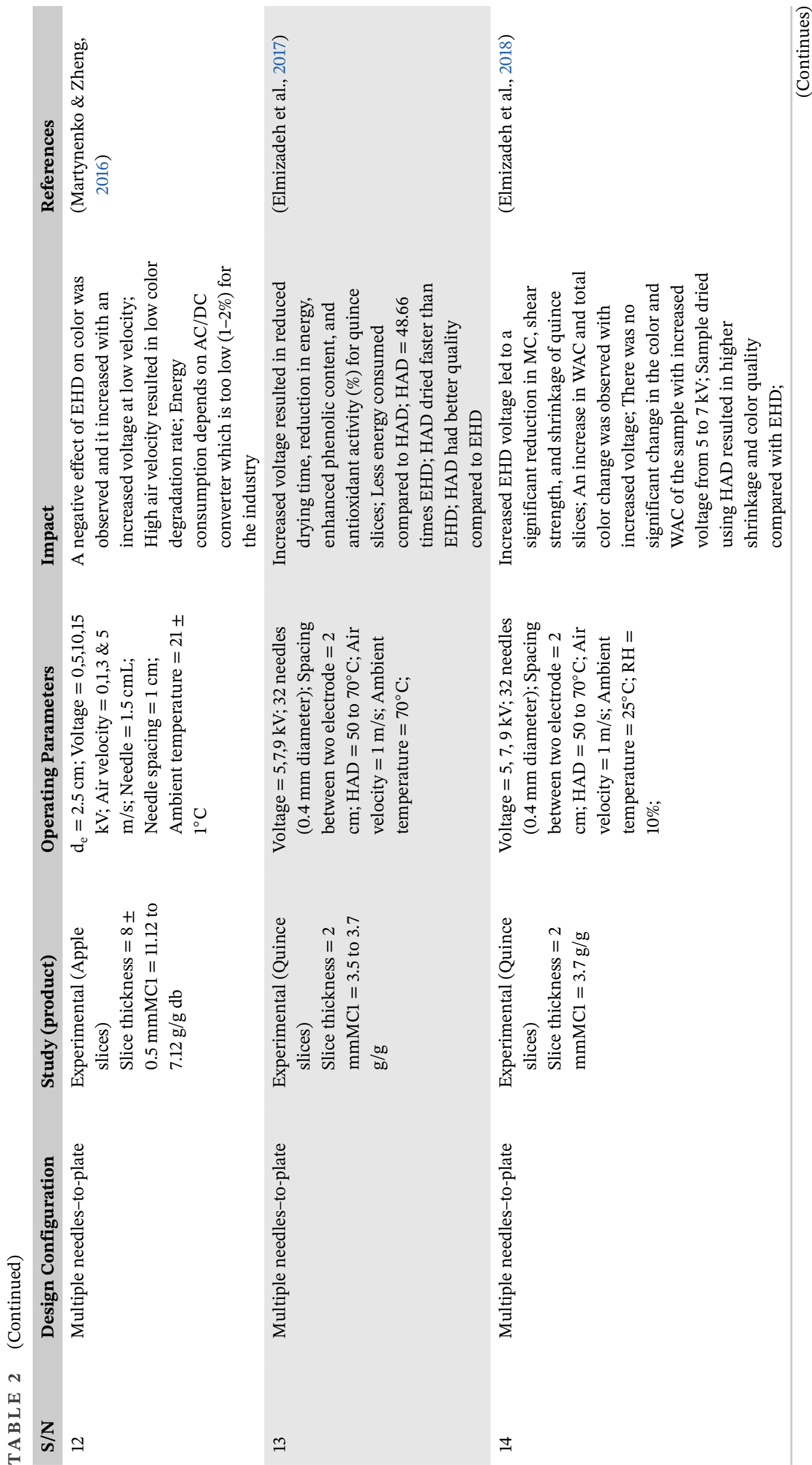

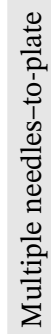

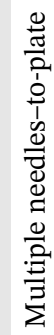

9 

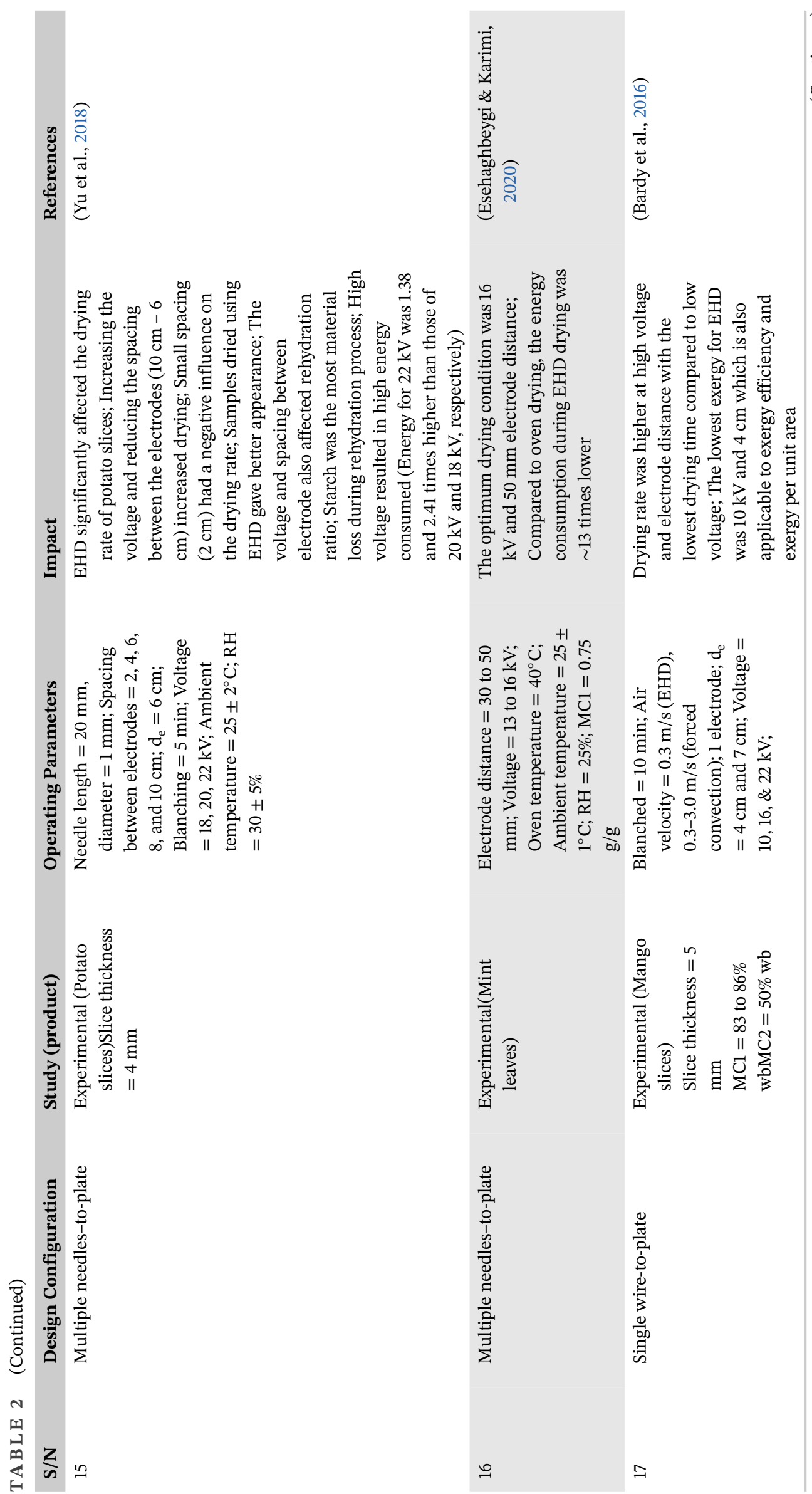

竞

$\div$

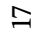



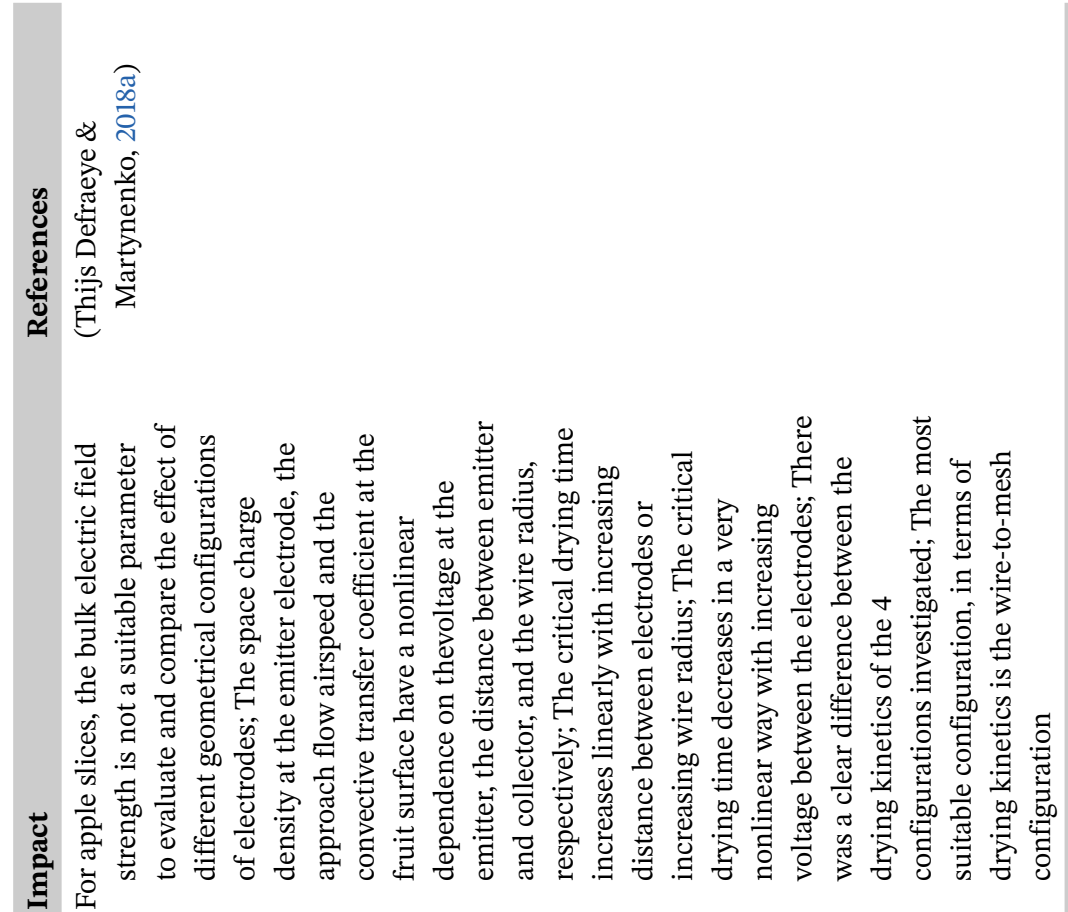

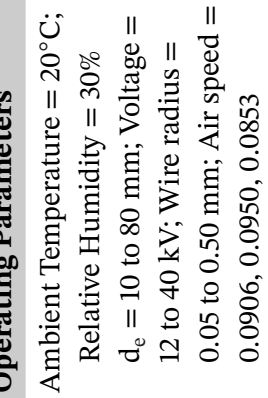

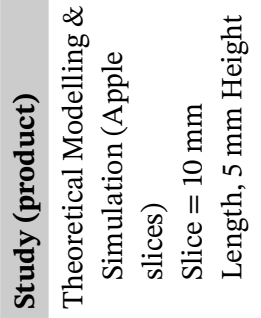
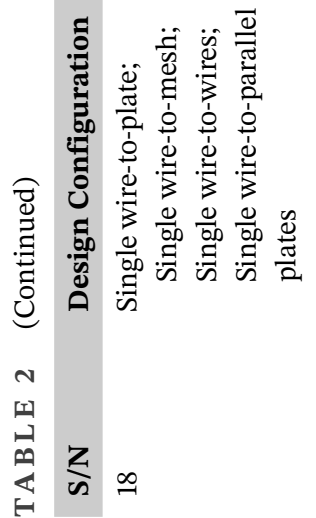


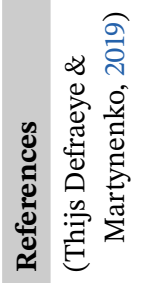

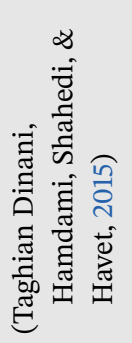

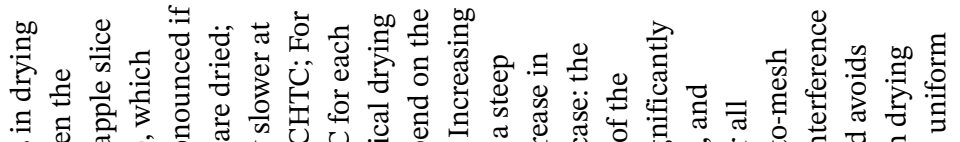

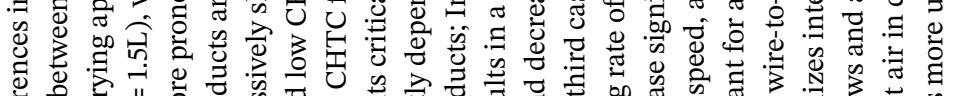

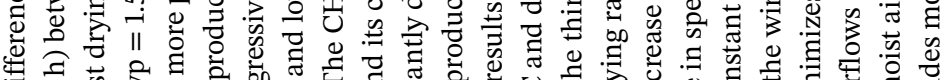

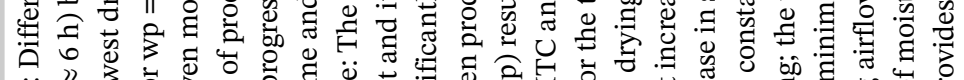

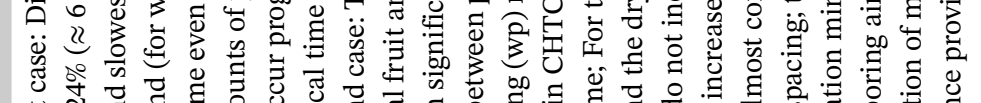

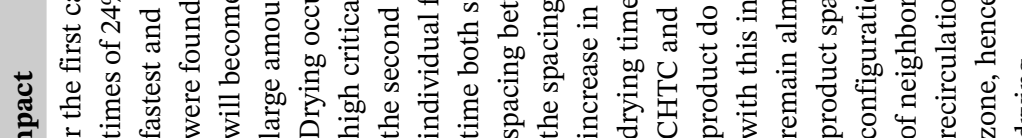

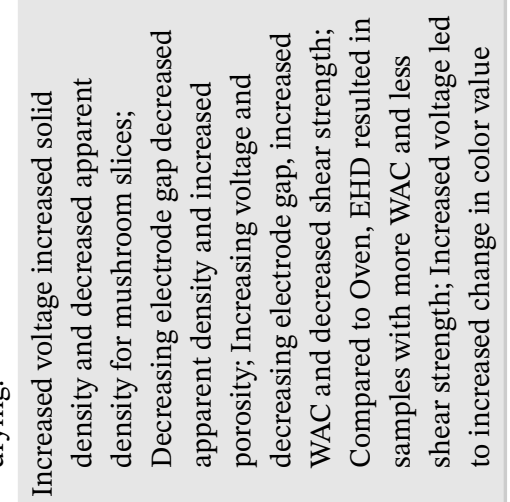

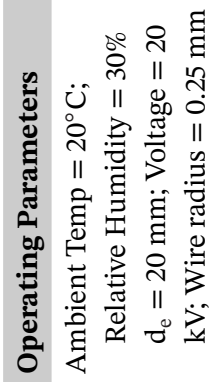

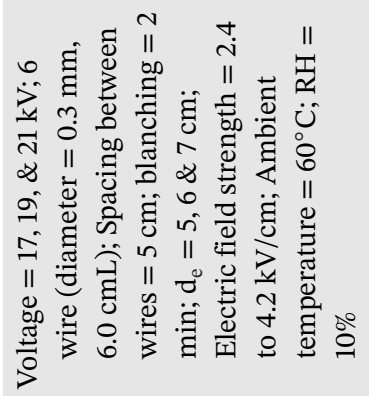

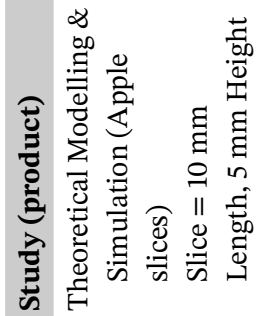
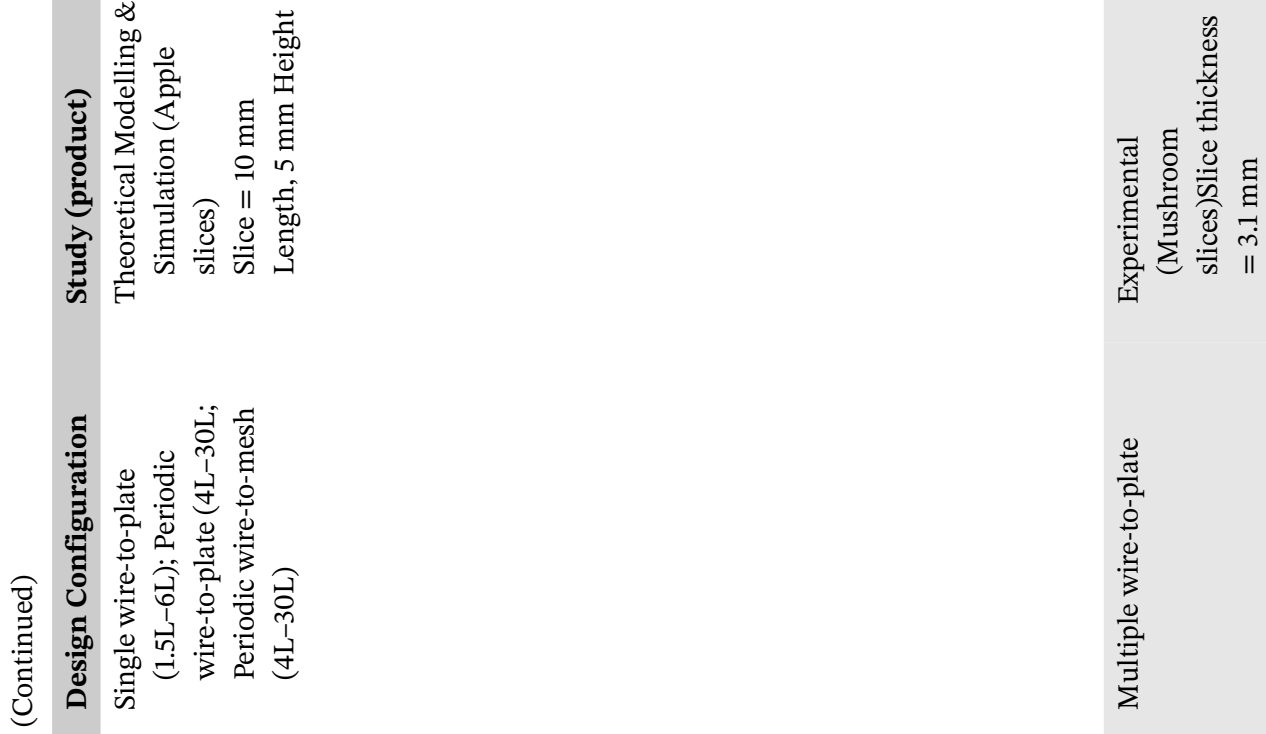

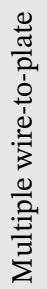

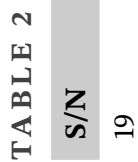



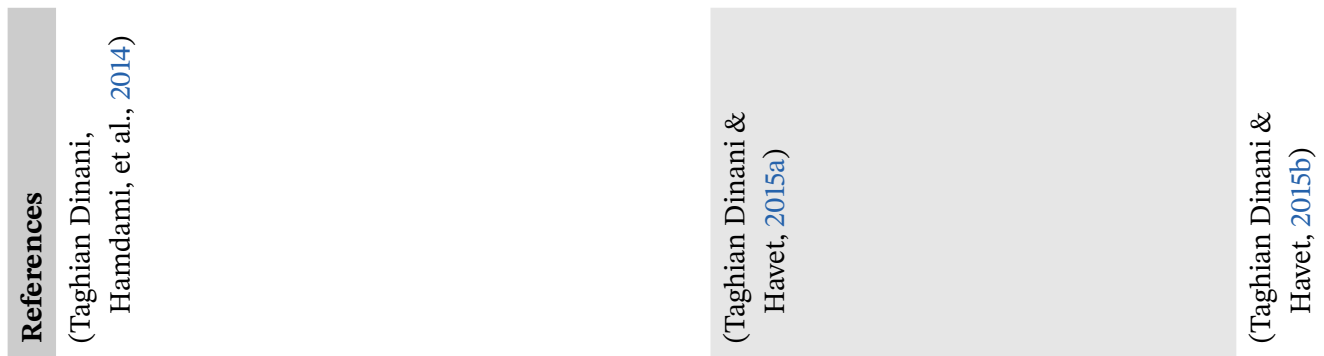

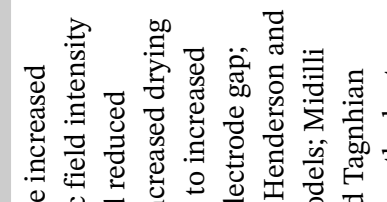

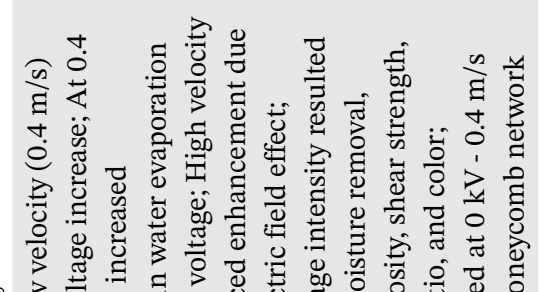

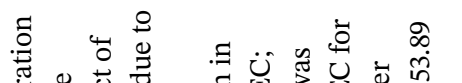

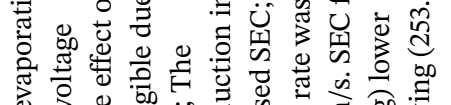

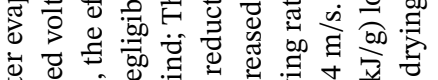

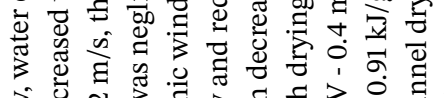

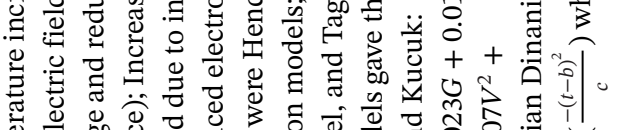

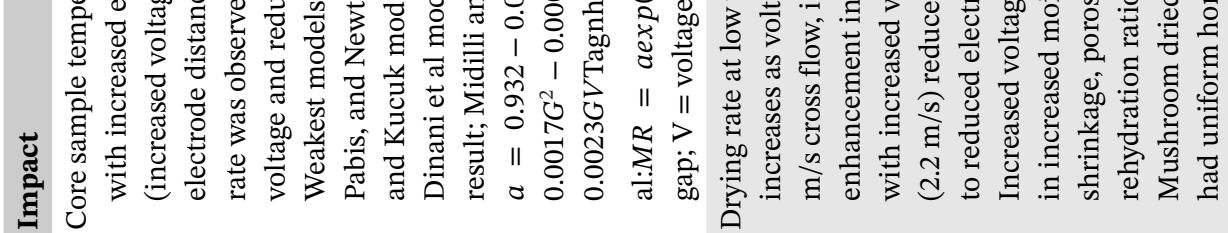

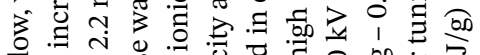

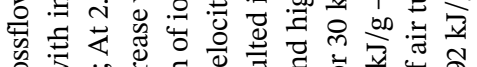

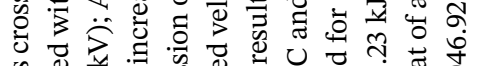

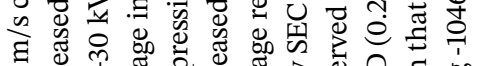

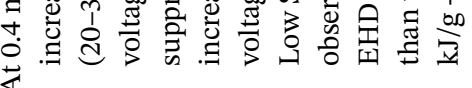
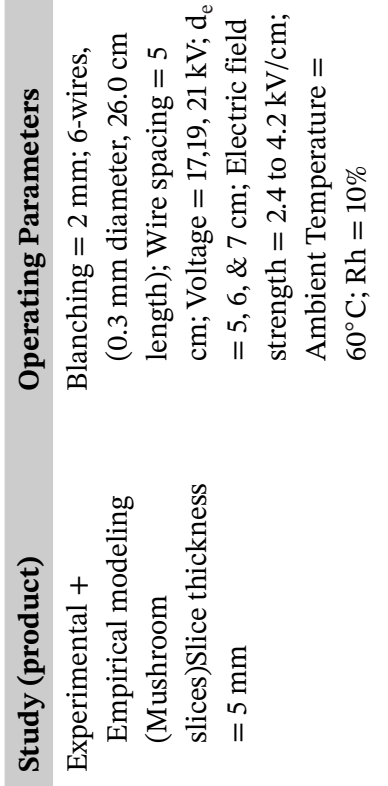

莺
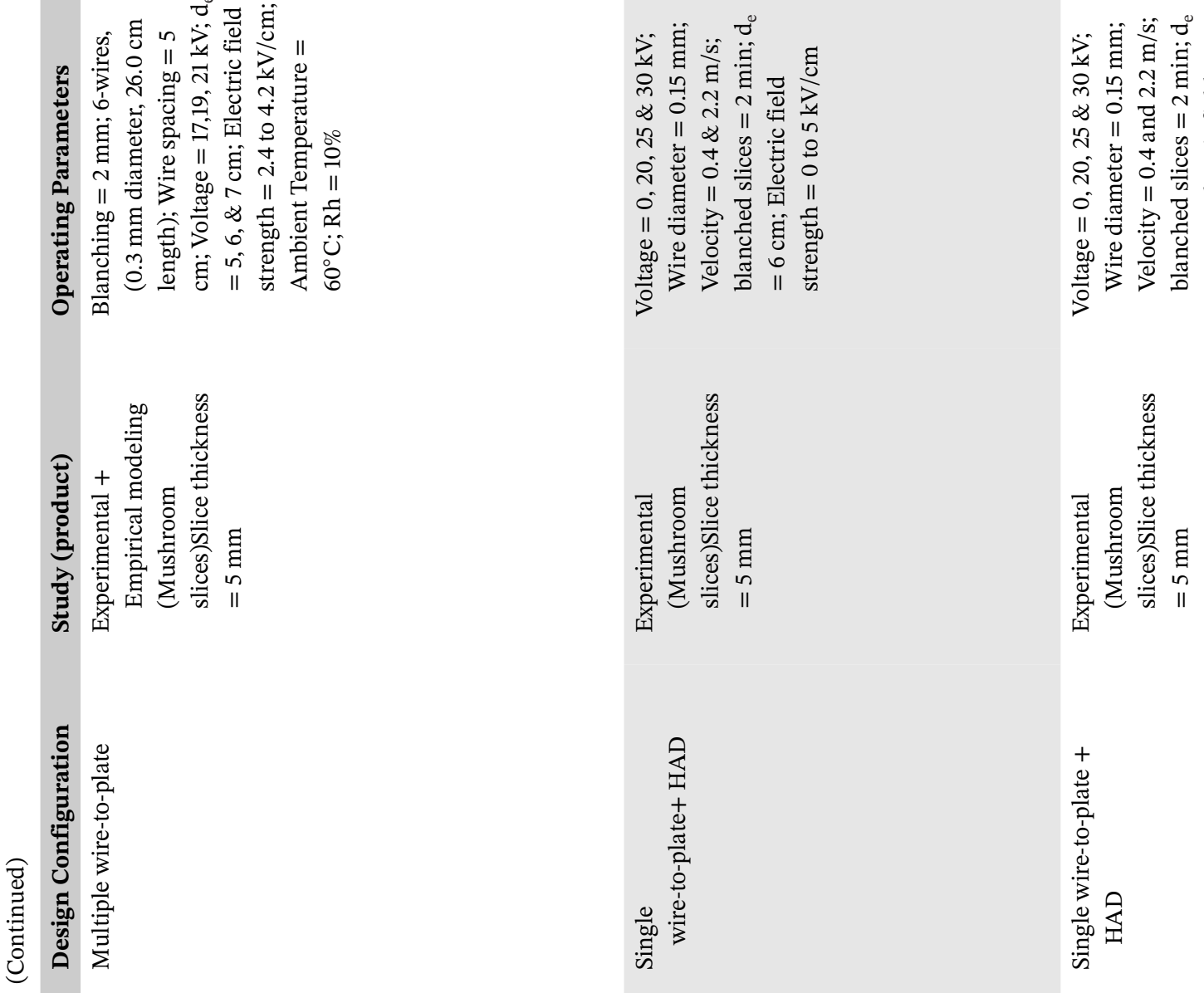

ส 

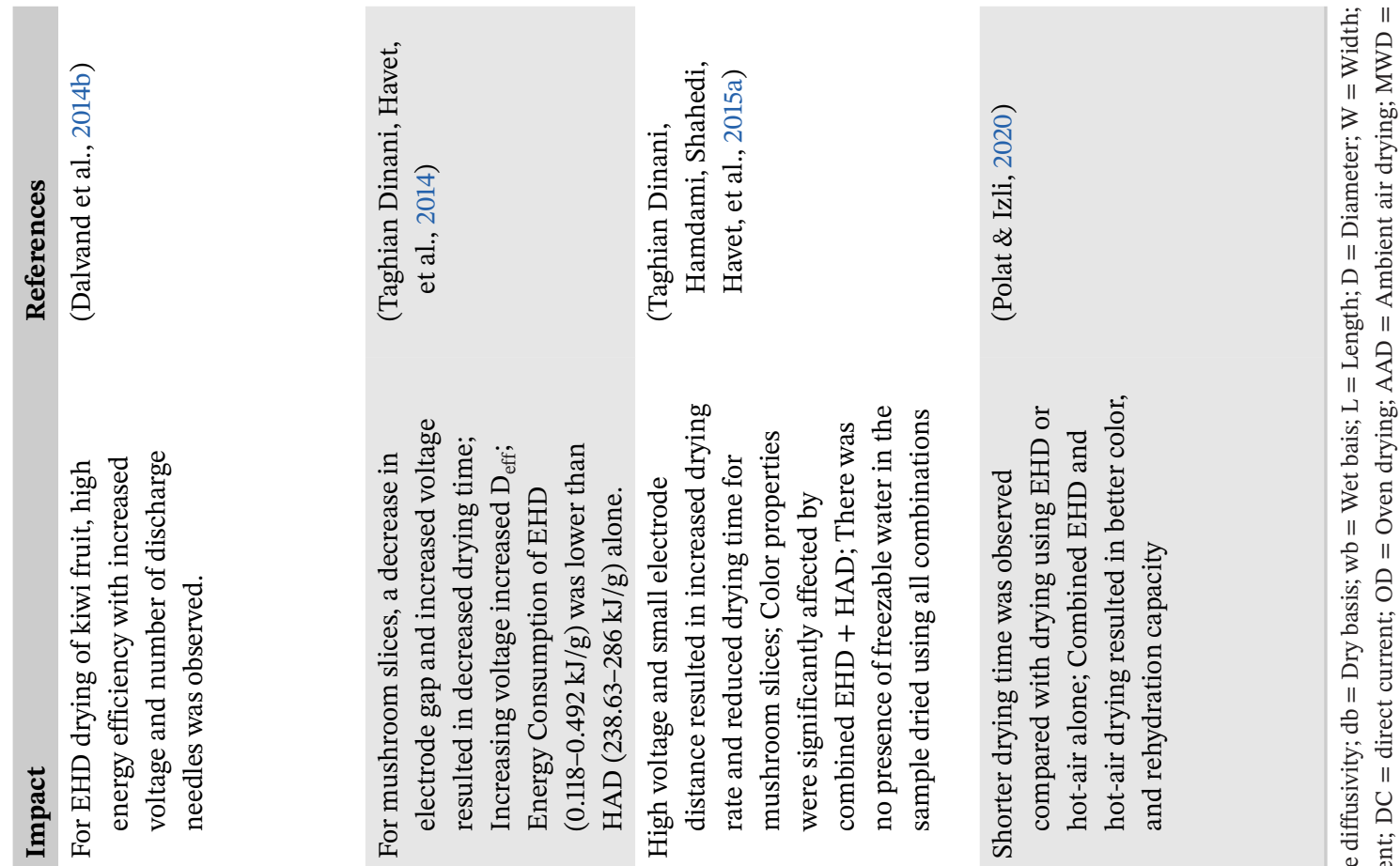

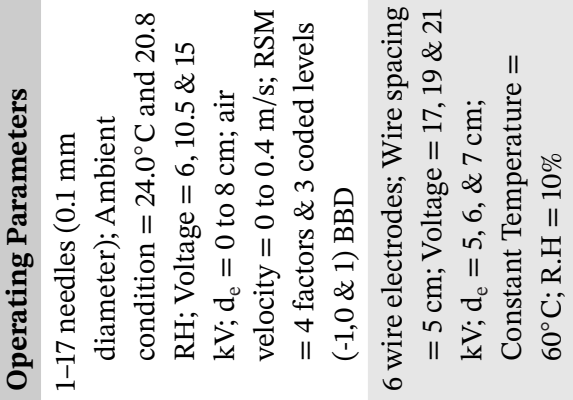

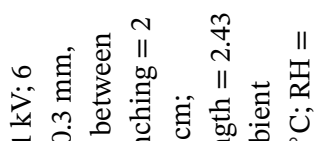

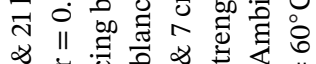
o : 今 II 矛苛 II

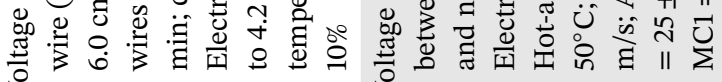
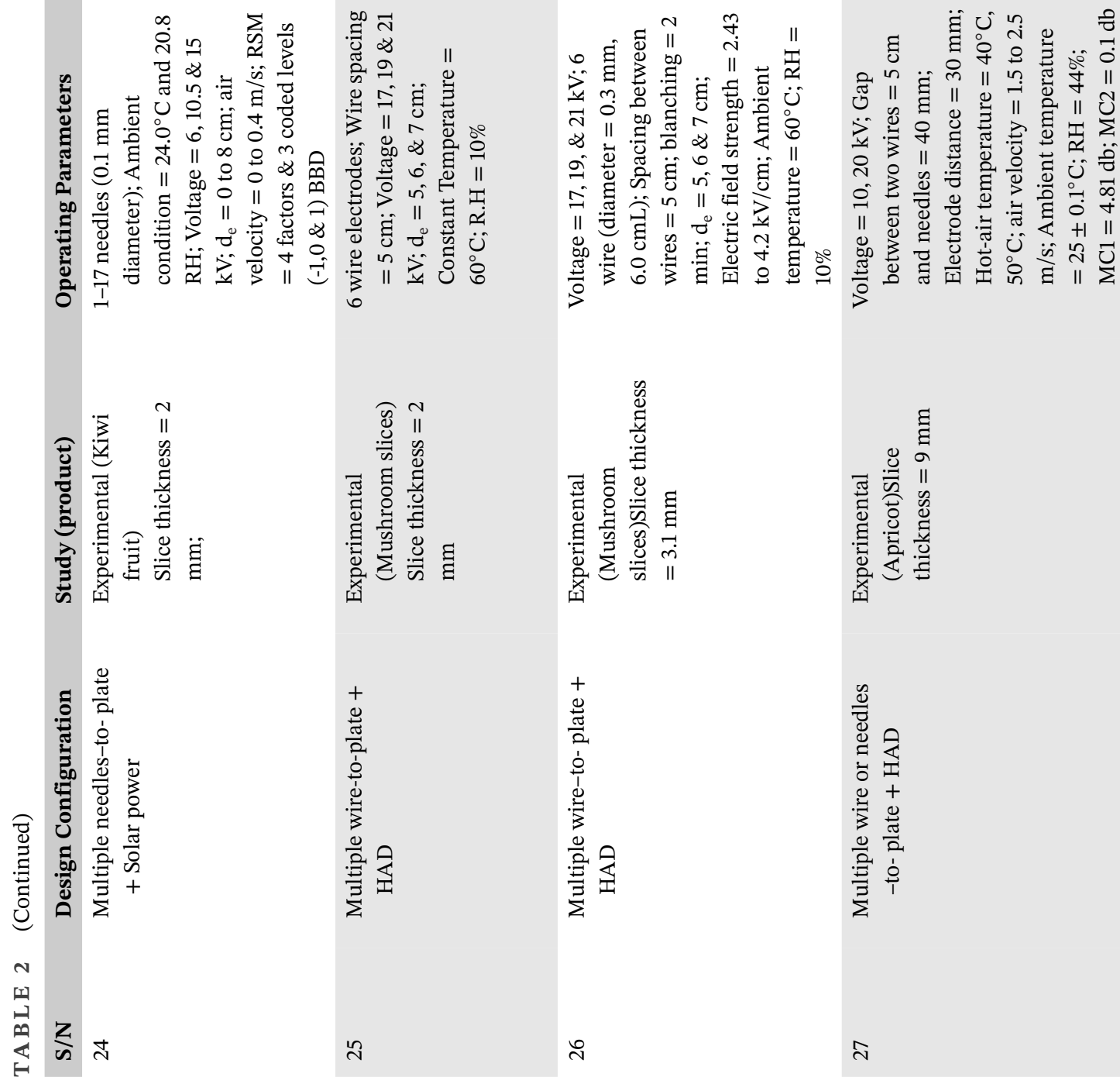

$\stackrel{2}{7}$

$\stackrel{i}{2}$

$\hat{\imath}$

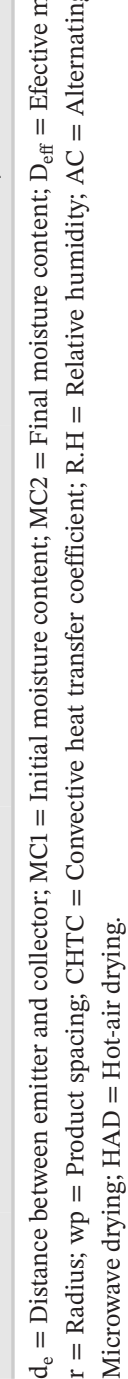




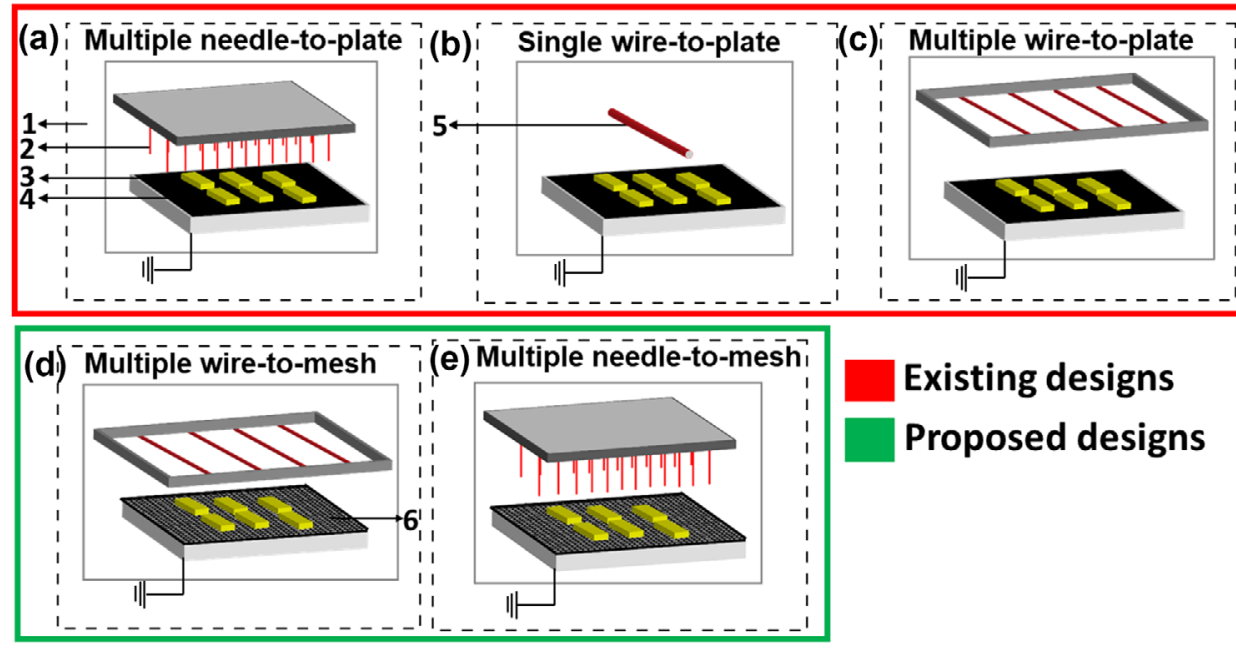

F I G U R E 4 Schematics diagram of types of EHD design configuration for multiple fruits and vegetables: $(1=$ drying chamber, $2=$ needle electrode, 3 = grounded plate collector, $4=$ sample, $5=$ wire electrode, $6=$ grounded-mesh collector)

toward the plate and are then redirected to the sides over the products. When air passes over successive products, successive saturation of the air with vapor will occur. This will reduce the drying rate of products downstream. Similarly, drying using multiple wires, a rebound of multiple air jets from the product can occur. This causes a partial saturation of the recirculating air, which slows down the drying rate. In order to successfully upscale the EHD drying technology, there is a need to design a collector electrode that would result in a uniform and faster drying process. This will thereby reduce the energy consumption needed to operate the equipment.

\subsection{3 | Are there practical solutions for the upscaling of EHD dryers?}

We consider whether it is practical to develop EHD collector electrode designs that would result in a uniform and faster drying with minimal energy requirement, which could stimulate industrial implementation. To answer this question, we illustrated different EHD design configurations in Figure 4 that, in our opinion, can overcome the drawbacks of the existing configurations. These configurations include the multiple wire-to-mesh configuration (Figure $4 \mathrm{~d}$ ) or the multiple needle-to-mesh configuration (Figure 4e).

EHD dryers using these configurations will be more likely to increase the drying rate due to the uniform airflow around the products compared to the existing labscale design configurations (Figure 4d-e). Defraeye \& Martynenko (2018) have recently predicted the suitability of the wire-to-mesh configuration over existing design con- figurations in a simulation-based study. This configuration minimizes the interference of neighboring airflows together with lower blockage of the air, thereby decreasing the recirculation of moist air in the drying environment. The unique aerodynamic impact of the grounded mesh collector on the drying rate of wet tissue was recently demonstrated by Martynenko et al. (2020). Iranshahi et al. (2020) further designed a high-energy efficient grounded mesh collector in-silico. This configuration uniformly dries products on all surfaces with an increased drying rate. However, some hurdles are still present when upscaling this electrode configuration, as discussed below.

\section{2 | Upscaling the EHD dryer using the wire-to-mesh configuration}

For effective upscaling of the EHD drying method, an energy and cost-efficient configuration that will produce dried fruits and vegetables of optimum quality is needed (Fylladitakis et al., 2014). From the analysis of the different EHD dryer configurations (Table 2), there is no known experimental study on EHD drying of fruits and vegetables using the wire-to-mesh configuration. This gap in information poses a barrier that must be overcome prior to the industrial implementation of the wire-to-mesh configuration.

To further develop the wire-to-mesh configuration for industrial upscaling, it is crucial to first demonstrate its scalability. This can be achieved by quantifying the impact of various processing variables on the drying kinetics, product quality, energy and cost-efficiency. These processing variables include the gaps between wire electrodes, 
geometry and size of electrode, product spacing, mesh size and spacing, sample thickness, and loading density. This information is important for process optimization and scaling of the EHD drying process. The impact of the fruit loading density on the mesh is particularly important in optimizing the dryer. We cannot load the trays too densely, probably as then airflow is restricted and the electrostatic field and ion flow can also be negatively affected. In addition, the mesh collector design (e.g., number of wires, the diameter of wires) plays a role in dryer optimization.

\section{3 | What are the general design considerations for a scalable EHD dryer?}

In designing a scalable EHD dryer for fruits and vegetables, the following vital requirements should be taken into consideration:

1. The product, electrode geometry and properties, as well as the ambient conditions, should be satisfactory for an efficient drying process.

2. The use of space and material should be economical.

3. The emitter electrodes should have sharp edges, so large curvature.

4. A wire mesh collector should be used for a uniform and fast drying process.

5. The collector electrode should be grounded or connected to a negative voltage.

6. Emitter should be connected to a positive DC supply as it is more energy and drying throughput efficient than negative DC.

7. The emitter electrodes should be placed directly above a grounded mesh collector.

8. The voltage at the emitter electrode should be high enough to cause a corona discharge but not so high that it could result in noisy corona discharge or a complete breakdown of the air.

9. The gap between the emitter electrode and the collector electrode should be sufficient not to cause sparkover.

10. The dryer loading capacity should be high to be energy and drying rate efficient.

11. The dryer should be of sufficient rigid construction to withstand any mechanical distortion.

12. The material of construction should be non-corrosive and nontoxic.

13. The dryer should be easily assembled and dissembled.

It is worth mentioning this list is not exhaustive as EHD drying technology is novel. The development of an EHD dryer may also depend on the design experience of a pilot EHD dryer.

\section{4 | Energy consumption while upscaling}

The EHD electrode configuration can affect the energy performance of the drying process. Since by changing the electrode configuration, the local electrostatic and ion flow conditions will change. Kudra \& Martynenko (2015) indicated the importance of energy consumption as a key criterion in upscaling the EHD drying process. The main question remains: will there be major changes in energy consumption during upscaling, if there is, to what extent? It has already been established that the energy consumption (in the form of specific energy consumption) during EHD drying of fruits and vegetables can be lower than those of standard drying methods, depending on the drying conditions (Table 2). The specific energy consumption values for the EHD drying of fruits and vegetables with grounded plate electrodes range from $0.12 \mathrm{~kJ} / \mathrm{g}$ to $16.50 \mathrm{~kJ} / \mathrm{g}$ (Table 2). These values are comparable with that of the convective belt dryer $(3.8 \mathrm{~kJ} / \mathrm{g}$ to $4 \mathrm{~kJ} / \mathrm{g}$ (T Kudra \& Martynenko, 2015)) but significantly lower than that of standard hot-air drying (even at very low temperature (Motevali et al., 2011)), which is in the range of $180-1800 \mathrm{~kJ} / \mathrm{g}$ (Onwude et al., 2018; Onwude et al., 2016). The energy consumption for a convective drying process is mainly used to generate airflow (e.g., fan-driven) and heat the convective air. However, the SEC of a fan strongly depends on the fan type, the airspeed and the turbulence level it generates (Defraeye \& Martynenko, 2018). The values for EHD were evaluated based on laboratory-scale EHD systems. However, these values may change depending on the total energy consumed by high-voltage AC/DC converters, which could depend on the number of emitter electrodes, applied voltage, electrode distance, ion mobility in air, space charge density, electric field strength and the capacity of the EHD dryer (loading density affects the drying time). This implies that the total energy consumption when drying a few fruit products is expected to be several times higher than that of a fully-loaded commercial EHD dryer. It is foreseen that the energy efficiency of an industrial scale EHD dryer with the wire-to-mesh configuration will be higher, as the distribution of the electric field and the ionic flow will be more efficient. In any case, the energy consumption will depend on the interplay between different processing variables (Table 2) such as voltage, electrode distance, gap between electrodes, product spacing, amongst others.

\section{5 | How about hybrid EHD dryers?}

EHD is often seen as a passive technology for enhancing heat/mass transfer by altering the boundary layer 
flow in limited configurations. Compared to commercial hot-air, vacuum, freeze and microwave dryers, EHD may not necessarily result in a shorter drying time even though it is more energy-efficient. This raises the question of whether an upscaled EHD dryer can be used in a fast industrial food drying process. To answer this question, researchers have recently suggested the combination of EHD with other commercial dryers to reduce energy cost, reduce drying time and potentially improve product quality for the standard drying process. Taghian Dinani \& Havet (2015b) studied the hybrid EHD + hot air drying (HAD) of mushrooms and showed that at $0.4 \mathrm{~m} / \mathrm{s}$ crossflow, water evaporation increased. The effect of increased voltage was negligible due to the suppression of ionic wind by airflow from the fan. An increase in velocity and reduction in voltage resulted in decreased specific energy consumption (SEC). Taghian Dinani et al. (2014) had earlier stated that the energy consumption of EHD + HAD was lower than HAD for mushroom slices. Taghian Dinani et al. (2015) demonstrated that EHD + HAD significantly increased the total color change of dried mushroom slices compared to drying using HAD. The effect of a hybrid EHD dryer on the nutritional quality of dried products has not been accessed yet.

Generally, there are lots of open questions regarding the quality of dried products and energy consumption during hybrid EHD + HAD drying of fruits and vegetables. One of the poosible ways to overcome this conundrum is to apply EHD + HAD intermittently. This will imply the generation of ionic wind for a certain time (HAD = off), and then the application of $\operatorname{HAD}(\mathrm{EHD}=$ off $)$, thereby reducing the total energy requirement for a continuous EHD + HAD drying process. In this way, more uniform temperature distribution and redistribution could be achieved. This could also lead to an improvement in the quality of dried products. Nonetheless, we still need to rethink if it makes sense to combine EHD dryer with a tradiational drying method to further improve drying efficiency.

\section{6 | FUTURE TRENDS FOR EHD DRYING OF FRUITS AND VEGETABLES}

\section{1 | Perspective for nutritional content, sensory quality, and upscaling}

With a significant increase in the world population in the coming years (Cilluffo \& Ruiz, 2019), the demand for highly nutritious processed food will increase. This means that scientists and researchers will constantly be developing processes and technology to meet this demand.
We anticipate that the novel EHD drying will become widespread in producing highly nutritious dried fruits and vegetables.

\subsection{1 | Open questions}

Looking ahead, there are key questions that must be addressed before the enhancement of nutrient retention and sensory quality of EHD dried products can be achieved. In addition, these key questions must be answered for the successful upscaling of the EHD drying process for commercial purposes. These include:

- What is the impact of multiple EHD drying variables (e.g., voltage, electrode distance, product spacing) on the nutritional composition and sensory properties (e.g., vitamins, electrolytes, taste, flavor) of dried fruits and vegetables?

- What are the optimum processing variables to achieve the desired product quality and, at the same time, is energy efficient for EHD drying of multiple products using the wire-to-mesh configuration?

\subsection{2 | What are the opportunities for addressing these questions?}

EHD drying experiments using the wire-to-mesh configuration should be conducted to simultaneously measure nutritional content (e.g., vitamin C, carotenoid) and sensory properties (e.g., color, hardness) of dried fruits and vegetables. Temperature, humidity, and weight loss data should also be measured during such drying experiments.

The development of a process from a laboratory scale to an industrial scale is highly challenging. Several drying variables depend on the dryer scale; for example, the drying rate and critical drying time are strongly dependent on how much fruit is loaded in a dryer (Cárcel et al., 2011). In this regard, computational modeling and optimization techniques are becoming useful tools in making decisions about industrial-scale dryers. To further develop and scale the EHD dryer with wire-to-mesh configuration into industrial systems, we need to assess the effectiveness of loading the EHD dryer to full capacity over a wide range of operating conditions. This can be realized by modeling the EHD dryer with physics-based, finite element modeling methods. The scalability can then be quantified by showing the impact of fruit loading density on the performance (see section 3) of the EHD drying process. 


\section{2 | Perspective for small-scale farmers}

Rural farmers are still highly dependent on traditional open sun drying. This drying method has inherent limitations, including a high reduction of nutrients because of prolonged drying time, and high product loss due to inadequate drying environment, insects, birds and rodent attacks, and variations in solar load (Ekechukwu, 1999). Urban and semi-urban smallholders depend on solar dryers and convective fan-driven technology to dry food (Chen, 2019; Krause et al., 2019; Singh \& Gaur, 2020). However, these drying methods are time-consuming and often result in dried products of low nutritional and sensory quality. As already shown in this paper, EHD drying can be a promising alternative to the currently used drying methods in rural and urban farms.

Compared to solar dryers used by smallholder farmers, EHD drying can retain the total phenolic content of fruits by up to $95 \%$ (Elmizadeh et al., 2017) compared to $40 \%-80 \%$ retention for fruits dried using solar dryers (Lakshmi et al., 2018; Mongi, 2013). EHD also reduced total color degradation of fruits and vegetables by up to $16 \%$ compared to fruits dried using solar driers. This comparison is based on individual studies as no known studies compare the nutritional and sensory properties of EHD dried fruits and vegetables with those of solar-dried products under the same environmental conditions.

Notwithstanding, one of the expected hurdles toward implementing EHD drying technology for small-scale farmers is the issue of electric power supply for EHD drying. Most developing countries, especially in Sub-Sahara Africa, do not have a stable grid-connected electricity supply. Other commercial sources of energy are either unreliable or, for some farmers, too expensive. To overcome this setback, a solar-powered EHD dryer with a wire-tomesh configuration can be employed. In other words, a standalone EHD dryer can be coupled to a solar photovoltaic (PV) system that can power the high voltage generator. This hybrid EHD drying system has a high potential for small-scale farmers because photovoltaic solar panels are easily and readily available, with government subsidies in most developing countries. Besides, a solar-powered EHD dryer with multiple needle-to-plate configurations was found to be highly energy-efficient in the drying of kiwi fruit compared to a convective air dryer (Dalvand et al., 2014b). However, for a solar-powered EHD dryer to be sustainable, it should be made to be operational all year round in places with insufficient sunlight or during the winter/wet season. One way to achieve this is to incorporate thermal storage materials such as biomass. That means an intermittent drying mode where EHD is powered by the solar PV system after receiving little sun- light, while the biomass works when there is no sunlight. Another approach is to integrate a solar battery to extend the use of the energy generated by the PV system. In any case, the potential of a solar-powered EHD dryer still needs to be explored.

With respect to cost, depending on the fruit loading density, the total cost for the EHD dryer is anticipated to be lower than that of a convective hot-air dryer. This is because the energy cost for the convective hot-air dryer is significantly higher (1730\% increase in the energy used $(\mathrm{kJ})$ ) than that of the EHD dryer (Martynenko \& Zheng, 2016). However, the capital cost for EHD drying can be higher, depending on the set-up components. This capital cost for EHD drying devices includes the cost of AC/DC high voltage converter, emitter electrodes, collector electrodes, and the drying air chamber. The capital cost for a convective hot-air dryer includes the cost of the fan, heater, blower, and drying air chamber. A possible additional cost can come from the maintenance of the electrodes as they can attract dust.

Urban and rural farmers use different solar dryers to dry fruits and vegetables. Depending on the fruit loading capacity of the dryer and the materials of construction, the total cost of producing these dryers is quite low. Typical examples are the indirect solar dryer (90 kg-capacity) $=$ $\$ 220.29$ US, mixed-mode solar dryer (90 kg-capacity) = $\$ 151.79$ US, cabinet dryer (75 kg-capacity) $=\$ 20 \mathrm{US}$, and chamber dryer (200 kg-capacity) $=\$ 64.10$ US (Prakash et al., 2017; Selvanayaki \& Sampathkumar, 2017). For a standalone solar PV dryer, the cost of a $200 \mathrm{~W}$ rated dryer, including $5 \mathrm{PV}$ modules, batteries, and controllers, is about $\$ 1,080$ US (Ahsan et al., 2016). This is much higher than the cost of the aforementioned solar dryers. A solar-powered EHD dryer will have a higher capital cost due to the high voltage convertor and the electrodes. This added cost can be offset by the added product quality or the decrease in drying time, so increased throughput. The additional profit (e.g., the better nutritional quality of dried products) compared to fan-driven air and solar drying of fruits and vegetables makes that its potential should be further explored for small-scale farmers. It is worthy to note that other commercial dryers such as infrared and microwave may outperform a solar-powered EHD dryer due to lower capital cost and not so high energy cost. In any case, a tradeoff between capital cost, energy demand, product throughput, quality of dried product, and environmental impact is required in selecting an appropriate dryer for small-scale farmers. A more detailed study comparing EHD drying with traditional dryers (e.g., solar dryers, hot-air dryers, vacuum dryers, etc.) used by small-scale farmers based on these various performance indicators is required. 


\section{3 | Perspective for the industry}

Upscaling of available laboratory-scale technology has posed a challenge when considering the introduction of new processes. The future state of developing EHD drying technology with the wire-to-mesh configuration or other configuration for the industry would demonstrate scalability. Unfortunately, this has not been carried out.

Nevertheless, we compare the drying efficiency of an upscaled EHD dryer based on 25\% loading capacity with traditional air dryers. Loading an EHD dryer up to 25\% capacity (Defraeye \& Martynenko, 2019) dried food up to $\sim 2$ times faster compared to drying potatoes at the same loading density in a traditional air dryer (at $30^{\circ} \mathrm{C}$ drying air temperature) (Bon et al., 1997). Similarly, at a loading capacity of 25\%, drying of fruits using an EHD dryer can dry up to $40 \%$ faster compared to drying using a solar tunnel dryer at ambient air conditions (Bechoff et al., 2010). This means that it is faster to load an EHD dryer densely with food and dry than drying the same amount of food in an industrial traditional air dryer. However, it is challenging to compare standard forced convective drying airflow field with EHD driven airflow. The reason is that a proper comparison should imply that the airflow rates are about the same.

A core requirement inherent in producing highly nutritious dried products in commercial quantities is the effective monitoring of the drying process. Current technologies used in the food industry are generally autonomous and record key drying parameters such as temperature and relative humidity. For EHD drying, the electric current and power also need to be monitored during the drying process.

Another problem for future implementation of the EHD drying technology in the industry is engineering ergonomics (industrial hygiene, safety, and maintenance). Engineering ergonomics simply means manmachine interaction in an industry. Over time, the surface of the EHD dryer emitter and collector electrodes will be covered with dust or corroded. This can affect the performance of the EHD, so a periodic cleaning of electrodes is required. Drying is often a unit operation that leads to another unit operation in the food industry. In other words, dryers are installed in continuous lines with other processing equipment such as roaster, separator, destoner, and grinder. Due to the different operating requirements of these unit operations, implementing the EHD drying in this way may affect the drying rate of the products.

Furthermore, the EHD dryer can cause a disturbance that affects electrostatic forces (electromagnetic interference) and audible noise. This can significantly affect the accuracy of sensor measurements. The installation of an EHD dryer in a typical food industry would involve grounding of the wire-to-mesh collector. This could also pose a problem if not adequately done. This is because grounded systems sometimes carry current flow, which can cause lightning strikes that can lead to severe accidents or injury. Therefore, the design of the EHD drying equipment area must be properly done from the beginning and must pass interference, emissions, and electrical safety tests.

\section{7 | CONCLUSION}

A scalable EHD dryer should be able to provide dried products of high nutritional density, with a low amount of energy and production cost. It should also have less impact on the environment compared to the available standard drying methods. In this review, we have described some pathways which put this exciting goal within our reach. This paper presented an overview of the current state and future perspectives of EHD drying of fruits and vegetables concerning nutritional and sensory quality, as well as its scalability. We also highlighted the research directions that are essential for improving the quality of dried fruits and vegetables and upscaling the EHD drying process, but are still underdeveloped. To help pave the way for the design of up-scaled EHD dryers that provide nutrient-dense and sensory appealing dried fruit and vegetables, this study concludes with the following:

- EHD drying improves the retention of vitamin C ( $25 \%)$, carotene $(\sim 10 \%)$, polysaccharides ( 24\%), flavonoid $(\sim 18 \%)$, color, and enhanced the rehydration capacity and textural quality of dried fruits and vegetables compared to standard convective drying methods.

- Nutritional and sensory quality of EHD dried fruits and vegetables are significantly affected by the applied voltage, electrode distance, and gaps between electrodes.

- Simultaneous measurements of different nutritional compositions and sensory properties of a certain fruit or vegetable are recommended for EHD drying. Here, the impact of EHD drying variables should be quantified, such as the applied voltage and the gaps between electrodes.

- The wire-to-mesh dryer configuration is the most suitable for upscaling the EHD drying process of fruits and vegetables and will likely also be more energy-efficient. The impact of the fruit loading density on the drying kinetics and energy consumption of this EHD wire-tomesh dryer is still to be quantified.

- It is also interesting to note that hybrid EHD drying of fruits and vegetables has received limited attention. Future studies should explore the development of hybrid 
EHD dryers for the industry as well as small-scale farmers.

- Adequate data comparing the upscalable EHD dryer in terms of cost, energy demand, and quality of dried products with commercially available dryers such as freeze dryer, microwave dryer, vacuum dryer, and infrared dryer are required.

\section{ACKNOWLEDGMENTS}

D.I.O. is grateful to the Swiss State Secretariat for Education, Research and Innovation (SERI) via the Federal Commission for Scholarships (ESKAS - 2019.0643) and the Swiss National Science Foundation SNSF (project IZSEZ0_186498) for the financial support provided during project conceptualization and execution.

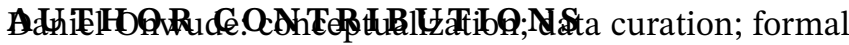
analysis; investigation; methodology; project administration; resources; supervision; validation; writing-original draft; writing-review and editing. Kamran Iranshahi: investigation; writing-review and editing. Alex Martynenko: investigation; supervision; writing-review and editing. Thijs Defraeye: conceptualization; investigation; methodology; project administration; supervision; writing-review and editing.

\section{CONFLICT OF INTEREST}

The authors declare no conflict of interest.

\section{ORC I D}

Daniel I. Onwude (1) https://orcid.org/0000-0002-2690-

5823

Kamran Iranshahi (i) https://orcid.org/0000-0001-5567-

8263

Thijs Defraeye (10 https://orcid.org/0000-0002-9835-5859

\section{REFERENCES}

Ahsan, S., Javed, K., Rana, A. S., \& Zeeshan, M. (2016). Design and cost analysis of $1 \mathrm{~kW}$ photovoltaic system based on actual performance in Indian scenario. Perspectives in Science, $\quad 8, \quad 642-644 . \quad$ https://doi.org/10.1016/j.pisc.2016.06.0 44

Alemrajabi, A. A., Rezaee, F., Mirhosseini, M., \& Esehaghbeygi, A. (2012). Comparative evaluation of the effects of electrohydrodynamic, oven, and ambient air on carrot cylindrical slices during drying process. Drying Technology, 30(1), 88-96. https://doi.org/10. 1080/07373937.2011.608913

Amoasah, B., Appiah, F., Tandoh, P., \& Amoateng, E. (2019). Effect of different drying methods on the mineral content of three accessions of Roselle (Hibiscus sabdariffa) calyces. Asian Journal of Advanced Research and Reports, 5(3), 1-10. https://doi.org/10. 9734/ajarr/2019/v5i330133

Antonio-Gutiérrez, O. T., López-Díaz, A. S., López-Malo, A., Palou, E., \& Ramírez-Corona, N. (2019). UV-C light for processing bev- erages: Principles, applications, and future trends. In: Processing and Sustainability of Beverages. Elsevier Inc., Cambridge. https://doi.org/10.1016/b978-0-12-815259-1.00007-0

Asami, D. K., Hong, Y. J., Barrett, D. M., \& Mitchell, A. E. (2003). Comparison of the total phenolic and ascorbic acid content of freeze-dried and air-dried marionberry, strawberry, and corn grown using conventional, organic, and sustainable agricultural practices. Journal of Agricultural and Food Chemistry, 51(5), 12371241. https://doi.org/10.1021/jf020635c

Bajgai, T. R., Raghavan, G. S. V., Hashinaga, F., \& Ngadi, M. O. (2006). Electrohydrodynamic drying - A concise overview. Drying Technology, 24(7), 905-910. https://doi.org/10.1080/07373930600734091

Bardy, E., Manai, S., Havet, M., \& Rouaud, O. (2016). Drying kinetics comparison of methylcellulose gel versus mango fruit in forced convective drying with and without electrohydrodynamic enhancement. Journal of Heat Transfer, 138(8). https://doi.org/10. $1115 / 1.4033390$

Bechoff, A., Westby, A., Owori, C., Menya, G., Dhuique-Mayer, C., Dufour, D., \& Tomlins, K. (2010). Effect of drying and storage on the degradation of total carotenoids in orange-fleshed sweetpotato cultivars. Journal of the Science of Food and Agriculture, 90(4), 622629. https://doi.org/10.1002/jsfa.3859

Belessiotis, V., \& Delyannis, E. (2011). Solar drying. Solar Energy, 85(8), 1665-1691. https://doi.org/10.1016/j.solener.2009.10.001

Berk, Z. (2018). Dehydration. In: Food Science and Technology (pp. 513-566). Academic Press, London. https://doi.org/10.1016/ B978-0-12-812018-7.00022-1

Bon, J., Simal, S., Rosselló, C., \& Mulet, A. (1997). Drying characteristics of hemispherical solids. Journal of Food Engineering, 34(2), 109-122. https://doi.org/10.1016/S0260-8774(97)00098-8

Bualuang, O., Onwude, D. I., \& Pracha, K. (2017). Microwave drying of germinated corn and its effect on phytochemical properties. Journal of the Science of Food and Agriculture, 97(9), 2999-3004. https://doi.org/10.1002/jsfa.8140

Cárcel, J. a., Garcia-Perez, J. V., Riera, E., \& Mulet, a. (2011). Improvement of convective drying of carrot by applying power ultrasound-Influence of mass load density. Drying Technology, 29(2), 174-182. https://doi.org/10.1080/07373937.2010.483032

Chang, S. K., Alasalvar, C., \& Shahidi, F. (2016). Review of dried fruits: Phytochemicals, antioxidant efficacies, and health benefits. Journal of Functional Foods, 21, 113-132. https://doi.org/10.1016/j.jff. 2015.11.034

Chen, M. (2019). Development of pico solar crop dryer (POD) for farm level grain drying by small holder farmers in Africa (master's thesis). Retrieved from: https://doi.org/10.25394/PGS.9108389.v1

Cilluffo, A., \& Ruiz, N. G. (2019). World's population is projected to nearly stop growing by the end of the century. https://www.pewresearch.org/fact-tank/2019/06/17/ worlds-population-is-projected-to-nearly-stop-growing-by-the -end-of-the-century/.

Codex Alimentarius Commission. (2017). Proposed draft guidelines for ready-to-use therapeutic foods. In: Joint FAO/WHO Food Standards Programme Codex Committee on Nutrition and Foods for Special Dietary Uses (Vol., 4, Issue (9)). https://doi.org/10.1017/ CBO9781107415324.004

Correia, P. N., Alkhatrash, A., Williams, C. E., Briley, A., Carter, J., Poston, L., \& Hosey, M.-T. (2017). What do expectant mothers need to know about oral health? A cohort study from a London maternity unit. BDJ Open, 3(1). https://doi.org/10.1038/bdjopen.2017.4 
Dalvand, M. J., Mohtasebi, S. S., \& Rafiee, S. (2013). Effect of needle number on drying rate of kiwi fruit in EHD drying process. Agricultural Sciences, 04(01), 1-5. https://doi.org/10.4236/as.2013.41001

Dalvand, M. J., Mohtasebi, S. S., \& Rafiee, S. (2014a). Modeling of electrohydrodynamic drying process using response surface methodology. Food Science and Nutrition, 2(3), 200-209. https://doi.org/ 10.1002/fsn3.96

Dalvand, M. J., Mohtasebi, S. S., \& Rafiee, S. (2014b). Optimization on drying conditions of a solar electrohydrodynamic drying system based on desirability concept. Food Science and Nutrition, 2(6), 758-767. https://doi.org/10.1002/fsn3.168

Defraeye, T., \& Martynenko, A. (2018). Future perspectives for electro-hydrodynamic drying of biomaterials. Drying Technology, 36(1), 1-10.

Defraeye, T., \& Martynenko, A. (2018a). Electrohydrodynamic drying of food: New insights from conjugate modeling. Journal of Cleaner Production, 198, 269-284. https://doi.org/10.1016/j.jclepro.2018.06. 250

Defraeye, T., \& Martynenko, A. (2019). Electrohydrodynamic drying of multiple food products: Evaluating the potential of emittercollector electrode configurations for upscaling. Journal of Food Engineering, 240, 38-42. https://doi.org/10.1016/j.jfoodeng.2018. 07.011

Ding, C., Lu, J., \& Song, Z. (2015). Electrohydrodynamic drying of carrot slices. Plos One, 10(4), 1-12. https://doi.org/10.1371/journal. pone. 0124077

Dominick, S. R., Fullerton, C., Widmar, N. J. O., \& Wang, H. (2018). Consumer Associations with the "All Natural" Food Label. Journal of Food Products Marketing, 24(3), 249-262. https://doi.org/10. 1080/10454446.2017.1285262

Ekechukwu, O. V. (1999). Review of solar energy drying systems I - An overview of drying principles and theory. Energy Conversion and Management, 40(6), 593-613. https://doi.org/10.1016/ S0196-8904(98)00092-2

Elmizadeh, A., Shahedi, M., \& Hamdami, N. (2017). Comparison of electrohydrodynamic and hot-air drying of the quince slices. Innovative Food Science and Emerging Technologies, 43(April), 130-135. https://doi.org/10.1016/j.ifset.2017.07.030

Elmizadeh, A., Shahedi, M., \& Hamdami, N. (2018). Quality assessment of electrohydrodynamic and hot-air drying of quince slice. Industrial Crops and Products, 116(August 2017), 35-40. https:// doi.org/10.1016/j.indcrop.2018.02.048

Esehaghbeygi, A., \& Basiry, M. (2011). Electrohydrodynamic (EHD) drying of tomato slices (Lycopersicon esculentum). Journal of Food Engineering, 104(4), 628-631. https://doi.org/10.1016/j. jfoodeng.2011.01.032

Esehaghbeygi, A., Pirnazari, K., \& Sadeghi, M. (2014). Quality assessment of electrohydrodynamic and microwave dehydrated banana slices. LWT - Food Science and Technology, 55(2), 565-571. https://doi.org/10.1016/j.lwt.2013.10.010

Esehaghbeygi Ali, Karimi Zahra (2020). Electrohydrodynamic, oven and natural drying of mint leaves and effects on the physiochemical indices of the leaves. Research in Agricultural Engineering, 66, (No. 3), 81-88. https://doi.org/10.17221/16/2020-rae.

FAO/WHO Expert Consultation. (2005). Human Vitamin and Mineral Requirements (2nd ed, p. 341). World Health Organization, Geneva. http://apps.who.int/iris/handle/10665/42716

Filippini, T., Violi, F., D’Amico, R., \& Vinceti, M. (2017). The effect of potassium supplementation on blood pressure in hyperten- sive subjects: A systematic review and meta-analysis. International Journal of Cardiology, 230, 127-135. https://doi.org/10.1016/ j.ijcard.2016.12.048

Fylladitakis, E. D., Theodoridis, M. P., \& Moronis, A. X. (2014). Review on the history, research, and applications of electrohydrodynamics. IEEE Transactions on Plasma Science, 42(2), 358-375. https://doi.org/10.1109/TPS.2013.2297173

Galanakis, C. M., Barba, F. J., \& Prasad, K. N. (2015). Cost and safety issues of emerging technologies against conventional techniques. In Food waste recovery: Processing technologies and industrial techniques. Elsevier Inc. https://doi.org/10.1016/B978-0-12-800351-0. 00014-6

García-Martínez, E., Igual, M., Martín-Esparza, M. E., \& MartínezNavarrete, N. (2013). Assessment of the Bioactive Compounds, Color, and Mechanical Properties of Apricots as Affected by Drying Treatment. Food and Bioprocess Technology, 6(11), 3247-3255. https://doi.org/10.1007/s11947-012-0988-1

Huang, L. 1., \& Zhang, M. (2012). Trends in Development of Dried Vegetable Products as Snacks. Drying Technology, 30(5), 448-461. https://doi.org/10.1080/07373937.2011.644648

İncedayi, B., Tamer, C. E., Sinir, G. Ö., Suna, S., \& Çopur, Ö. U. (2016). Impact of different drying parameters on color, $\beta$-carotene, antioxidant activity and minerals of apricot (Prunus armeniaca L.). Food Science and Technology, 36(1), 171-178. https://doi.org/10. 1590/1678-457X.0086

Iranshahi, K., Martynenko, A., \& Defraeye, T. (2020). Cutting-down the energy consumption of electrohydrodynamic drying by optimizing mesh collector electrode. Energy, 208, 118168. https://doi. org/10.1016/j.energy.2020.118168

Izli, N., Yildiz, G., Ünal, H., Işik, E., \& Uylaşer, V. (2014). Effect of different drying methods on drying characteristics, colour, total phenolic content and antioxidant capacity of Goldenberry (Physalis peruviana L.). International Journal of Food Science and Technology, 49(1), 9-17. https://doi.org/10.1111/ijfs. 12266

Johansson I., Lif Holgerson P., Kressin N.R., Nunn M.E., Tanner A.C. (2010). Snacking Habits and Caries in Young Children. Caries Research, 44, (5), 421-430. https://doi.org/10.1159/000318569.

Jayaraman, K.S, \& Das Gupta, D.K (2014(Drying of Fruits and Vegetables. Handbook of Industrial Drying, 611-643). https://www.taylorfrancis.com/chapters/mono/10.1201/ b17208-42/drying-fruits-vegetables-arun-mujumdar?context= ubx\&refId=d2448902-a79e-4b61-96bf-af5baa19c861.

Kasper, H. U., Adermahr, J., \& Dienes, H. P. (2014). Next Generation Drying Technologies for Pharmaceutical Applications. Journal of Pharmaceutical Sciences, 103, 2673-2695. https://doi.org/10.1002/ jps. 23998

Kong, H., \& Chandel, N. S. (2020). Reactive oxygen species and cancer. In Oxidative Stress. Elsevier Inc. https://doi.org/10.1016/ b978-0-12-818606-0.00030-4

Krause, H., Faße, A., \& Grote, U. (2019). Nutrient-dense crops for rural and peri-urban smallholders in Kenya-A regional social accounting approach. Sustainability (Switzerland), 11(11). https:// doi.org/10.3390/su11113017

Kudra, T., \& Martynenko, A. (2015). Energy aspects in electrohydrodynamic drying. Drying Technology, 33(13), 1534-1540. https://doi.org/10.1080/07373937.2015.1009540 
Kudra, T., \& Martynenko, A. (2019). Electrohydrodynamic drying: Theory and experimental validation. Drying Technology, 0(0), 1-8. https://doi.org/10.1080/07373937.2019.1628773

Lakshmi, D. V. N., Muthukumar, P., Layek, A., \& Nayak, P. K. (2018). Drying kinetics and quality analysis of black turmeric (Curcuma caesia) drying in a mixed mode forced convection solar dryer integrated with thermal energy storage. Renewable Energy, 120, 23-34. https://doi.org/10.1016/j.renene.2017.12.053

Lai, F. C. (2010). A prototype of EHD-enhanced drying system. Journal of Electrostatics. https://doi.org/10.1016/j.elstat.2009.08.002

Liang, Y.-Z. (2000). High voltage electric field drying apparatus. Patent CN 2369184Y.

Liang, Y.-Z. (2002). High voltage electric field drying method and its electrostatic drying device. Patent CN 1348085A.

Madhava Naidu, M., Vedashree, M., Satapathy, P., Khanum, H., Ramsamy, R., \& Hebbar, H. U. (2016). Effect of drying methods on the quality characteristics of dill (Anethum graveolens) greens. Food Chemistry, 192, 849-856. https://doi.org/10.1016/j.foodchem.2015. 07.076

Martynenko, A., Astatkie, T., \& Defraeye, T. (2020). The role of convection in electrohydrodynamic drying. Journal of Food Engineering, 271(October 2019), 109777. https://doi.org/10.1016/j.jfoodeng. 2019.109777

Martynenko, A., Astatkie, T., Riaud, N., Wells, P., \& Kudra, T. (2017). Driving forces for mass transfer in electrohydrodynamic (EHD) drying. Innovative Food Science and Emerging Technologies, 43(July), 18-25. https://doi.org/10.1016/j.ifset.2017.07.022

Martynenko, A., \& Kudra, T. (2019). Electrohydrodynamic Drying. In A. S. Mujumdar \& H.-W. Xiao (Eds.), Advanced Drying Technologies for Foods (pp. 1-29). CRC Press Taylor and Francis Group. https://doi.org/10.1201/9780367262037

Martynenko, A., \& Zheng, W. (2016). Electrohydrodynamic drying of apple slices: Energy and quality aspects. Journal of Food Engineering, 168, 215-222. https://doi.org/10.1016/j.jfoodeng.2015.07.043

Mbondo, N. N., Owino, W. O., Ambuko, J., \& Sila, D. N. (2018). Effect of drying methods on the retention of bioactive compounds in African eggplant. Food Science and Nutrition, 6(4), 814-823. https://doi.org/10.1002/fsn3.623

Melanson, K. J. (2008). Nutrition Review: Lifestyle Approaches to Promoting Healthy Eating for Children. American Journal of Lifestyle Medicine, 2(1), 26-29. https://doi.org/10.1177/ 1559827607309217

Mongi, R. J (2013). Solar Drying of Fruits and Vegetables: Dryers' Thermal Performance, Quality and Shelf Life of Dried Mango, Banana, Pineapple, and Tomato. 136-141. http://www.suaire.sua. ac.tz/handle/123456789/496.

Moses, J. a., Norton, T., Alagusundaram, K., \& Tiwari, B. K. (2014). Novel Drying Techniques for the Food Industry. Food Engineering Reviews, 6(3), 43-55. https://doi.org/10.1007/s12393-014-9078-7

Motevali, A., Minaei, S., Khoshtaghaza, M. H., \& Amirnejat, H. (2011). Comparison of energy consumption and specific energy requirements of different methods for drying mushroom slices. Energy, 36(11), 6433-6441. https://doi.org/10.1016/j.energy.2011.09. 024

Mujumdar, A. S. (2000). Classification and selection of industrial dryers. In S. Devahastin (Ed.), Mujumdar's Practical Guide to Industrial Drying (pp. 23-36). Exergex Corporation.

Mujumdar, A. S., \& Zhonghua, W. (2007). Thermal Drying Technologies-Cost-Effective Innovation Aided by Mathe- matical Modeling Approach. Drying Technology, 26(1), 145-153. https://doi.org/10.1080/07373930701812606

Ni, J., Ding, C., Zhang, Y., Song, Z., Hu, X., \& Hao, T. (2019). Electrohydrodynamic Drying of Chinese Wolfberry in a Multiple Needleto-Plate Electrode System. Foods, 8(5), 152. https://doi.org/10.3390/ foods 8050152

Nkumah, O. C. (2016). Phytochemical analysis and medicinal uses of Hibiscus sabdariffa. International Journal of Herbal Medicine, January 2015.

Onwude, D. I., Hashim, N., Abdan, K., Janius, R., \& Chen, G. (2018). Investigating the influence of novel drying methods on sweet potato (Ipomoea batatas L .): Kinetics, energy consumption, color, and microstructure. Journal of Food Process Engineering, 41(4), e12686. https://doi.org/10.1111/jfpe.12686

Onwude, D. I., Hashim, N., \& Chen, G. (2016). Recent advances of novel thermal combined hot air drying of agricultural crops. Trends in Food Science \& Technology, 57, 132-145. https://doi.org/ 10.1016/j.tifs.2016.09.012

Onwude, D. I., Hashim, N., Janius, R., Abdan, K., Chen, G., \& Oladejo, A. O. (2017). Non-thermal hybrid drying of fruits and vegetables: A review of current technologies. Innovative Food Science and Emerging Technologies, 43, 223-238. https://doi.org/10.1016/j. ifset.2017.08.010

Pirasteh, G., Saidur, R., Rahman, S. M. A., \& Rahim, N. A. (2014). A review on development of solar drying applications. Renewable and Sustainable Energy Reviews, 31, 133-148. https://doi. org/10.1016/j.rser.2013.11.052

Pirnazari, K., Esehaghbeygi, A., \& Sadeghi, M. (2014). Assessment of quality attributes of banana slices dried by different drying methods. International Journal of Food Engineering, 10(2), 251260. https://doi.org/10.1515/ijfe-2013-0059

Pirnazari, K., Esehaghbeygi, A., \& Sadeghi, M. (2016). Modeling the electrohydrodynamic (EHD) drying of banana slices. International Journal of Food Engineering, 12(1), 17-26. https://doi.org/10.1515/ ijfe-2015-0005

Polat, A., \& Izli, N. (2020). Determination of drying kinetics and quality parameters for drying apricot cubes with electrohydrodynamic, hot air and combined electrohydrodynamic-hot air drying methods. Drying Technology, O(0), 1-16. https://doi.org/10.1080/ 07373937.2020.1812633

Prakash, O., Ranjan, S., Kumar, A., \& Gupta, R. (2017). Economic Analysis of Various Developed Solar Dryers. In O. Prakash \& A. Kumar (Eds.), Solar Drying Technology: Concept, Design, Testing, Modeling, Economics, and Environment (pp. 495-513). Springer Singapore. https://doi.org/10.1007/978-981-10-3833-4_17

Precoppe Marcelo, Janjai Serm, Mahayothee Busarakorn, Müller Joachim (2015). Batch uniformity and energy efficiency improvements on a cabinet dryer suitable for smallholder farmers. Journal of Food Science and Technology, 52, (8), 4819-4829. https://doi.org/ 10.1007/s13197-014-1544-y.

Rana, J., \& Paul, J. (2017). Consumer behavior and purchase intention for organic food: A review and research agenda. Journal of Retailing and Consumer Services, 38(May), 157-165. https://doi.org/10. 1016/j.jretconser.2017.06.004

Sablani, S. S. (2006). Drying of fruits and vegetables: Retention of nutritional/functional quality. Drying Technology, 24(2), 123-135. https://doi.org/10.1080/07373930600558904

Saneewong Na Ayuttaya, S., Chaktranond, C., Rattanadecho, P., \& Kreewatcharin, T. (2012). Effect of ground arrangements on 
swirling flow in a rectangular duct subjected to electrohydrodynamic effects. Journal of Fluids Engineering, Transactions of the ASME, 134(5), 15-18. https://doi.org/10.1115/1.4006699

Sarker, U., Oba, S., \& Daramy, M. A. (2020). Nutrients, minerals, antioxidant pigments and phytochemicals, and antioxidant capacity of the leaves of stem amaranth. Scientific Reports, 10(1), 1-9. https://doi.org/10.1038/s41598-020-60252-7

Selvanayaki, S., \& Sampathkumar, K. (2017). Techno-economic Analysis of Solar Dryers. In O. Prakash \& A. Kumar (Eds.), Solar Drying Technology: Concept, Design, Testing, Modeling, Economics, and Environment (pp. 463-493). Springer Singapore. https://doi.org/ 10.1007/978-981-10-3833-4_16

Scaglioni, S., De Cosmi, V., Mazzocchi, A., Bettocchi, S., \& Agostoni, C. (2017). Vegetarian Infants and Complementary Feeding. In Vegetarian and Plant-Based Diets in Health and Disease Prevention. Elsevier. https://doi.org/10.1016/B978-0-12-803968-7.00029-0

Sharma, G. P., \& Prasad, S. (2001). Drying of garlic (Allium sativum) cloves by microwave-hot air combination. Journal of Food Engineering, 50(2), 99-105. https://doi.org/10.1016/S0260-8774(00) 00200-4

Singh, P., \& Gaur, M. K. (2020). A Review on Role of Solar Drying Technology in Sustainable Development. In Pandit M., S L., V. R. R, \& B. J (Eds.), Bansal J. (eds) Intelligent Computing Applications for Sustainable Real-World Systems.ICSISCET 2019. Proceedings in Adaptation, Learning and Optimization, (vol 13). Springer, Cham.

Singh, S., \& Kumar, S. (2013). Solar drying for different test conditions: Proposed framework for estimation of specific energy consumption and $\mathrm{CO} 2$ emissions mitigation. Energy, 51, 27-36. https://doi.org/10.1016/j.energy.2013.01.006

Singh, A., Orsat, V., \& Raghavan, V. (2012). A Comprehensive Review on Electrohydrodynamic Drying and High-Voltage Electric Field in the Context of Food and Bioprocessing. Drying Technology, 30(16), 1812-1820. https://doi.org/10.1080/07373937.2012.708912

Slavin Joanne L., Lloyd Beate (2012). Health Benefits of Fruits and Vegetables. Advances in Nutrition, 3, (4), 506-516. https://doi.org/ 10.3945/an.112.002154.

Taghian Dinani, S., Hamdami, N., Shahedi, M., \& Havet, M. (2014). Mathematical modeling of hot air/electrohydrodynamic (EHD) drying kinetics of mushroom slices. Energy Conversion and Management, 86, 70-80. https://doi.org/10.1016/j.enconman.2014.05. 010

Taghian Dinani, S., Hamdami, N., Shahedi, M., \& Havet, M. (2015). Quality assessment of mushroom slices dried by hot air combined with an electrohydrodynamic (EHD) drying system. Food and Bioproducts Processing, 94(August), 572-580. https://doi.org/10.1016/ j.fbp.2014.08.004

Taghian Dinani, S., Hamdami, N., Shahedi, M., Havet, M., \& Queveau, D. (2015a). Influence of the electrohydrodynamic process on the properties of dried button mushroom slices: A differential scanning calorimetry (DSC) study. Food and Bioproducts Processing, 95, 83-95. https://doi.org/10.1016/j.fbp.2015.04.001

Taghian Dinani, S., \& Havet, M. (2015a). Effect of voltage and air flow velocity of combined convective-electrohydrodynamic drying system on the physical properties of mushroom slices. Industrial Crops and Products, 70, 417-426. https://doi.org/10.1016/j.indcrop. 2015.03.047

Taghian Dinani, S., \& Havet, M. (2015b). The influence of voltage and air flow velocity of combined convective-electrohydrodynamic drying system on the kinetics and energy consumption of mush- room slices. Journal of Cleaner Production, 95, 203-211. https://doi. org/10.1016/j.jclepro.2015.02.033

Taghian Dinani, S., Havet, M., Hamdami, N., \& Shahedi, M. (2014a). Drying of Mushroom Slices Using Hot Air Combined with an Electrohydrodynamic (EHD) Drying System. Drying Technology, 32(5), 597-605. https://doi.org/10.1080/07373937.2013.851086

Takamatsu. (2012). Tea leaf high-voltage electrostatic field dryer. Patent CN103859069A

Tan, H. Z., Li, Z. G., \& Tan, B. (2009). Starch noodles: History, classification, materials, processing, structure, nutrition, quality evaluating and improving. Food Research International, 42(5-6), 551-576. https://doi.org/10.1016/j.foodres.2009.02.015

Tippayawong, N., Tantakitti, C., \& Thavornun, S. (2008). Energy efficiency improvements in longan drying practice. Energy, 33(7), 1137-1143. https://doi.org/10.1016/j.energy.2008.02.007

Titcomb, T. J., \& Tanumihardjo, S. A. (2019). Global Concerns with B Vitamin Statuses: Biofortification, Fortification, Hidden Hunger, Interactions, and Toxicity. Comprehensive Reviews in Food Science and Food Safety, 18(6), 1968-1984. https://doi.org/10.1111/ 1541-4337.12491

Tuan, A., Tam, T., Ngoc, A., Lang, V., \& Chyuan, F. (2014). Application of EHD-enhanced drying technology: a sustainable approach for Vietnam's agricultural product processing in the future. J. Viet. Env, 6(3), 256-263. https://doi.org/10.13141/jve.vol6.no3.pp256-263

Vukasovič, T. (2016). 'Consumers' perceptions and behaviors regarding organic fruits and vegetables: Marketing trends for organic food in the twenty-first century. Journal of International Food and Agribusiness Marketing, 28(1), 59-73. https://doi.org/10.1080/ 08974438.2015.1006974

Wang, Y. (2013). Energy-efficient Industrial Dryers of Berries (Issue May). University of Gavle.

Yang, M., \& Ding, C. (2016). Electrohydrodynamic (EHD) drying of the Chinese wolfberry fruits. Springer Plus, 5(1), 909-929. https://doi.org/10.1186/s40064-016-2546-1

Yang, M., Ding, C., \& Zhu, J. (2017). The drying quality and energy consumption of Chinese wolfberry fruits under electrohydrodynamic system. International Journal of Applied Electromagnetics and Mechanics, 55(1), 101-112. https://doi.org/10.3233/JAE-170010

Yu, H. J., Bai, A. Z., Yang, X. W., \& Wang, Y. L. (2018). Electrohydrodynamic drying of potato and process optimization. Journal of Food Processing and Preservation, 42(2), 1-9. https://doi.org/10.1111/jfpp. 13492

Zhao, D., An, K., Ding, S., Liu, L., Xu, Z., \& Wang, Z. (2014). TwoStage Intermittent Microwave Coupled with Hot-Air Drying of Carrot Slices: Drying Kinetics and Physical Quality. Food and Bioprocess Technology, 7(8), 2308-2318. https://doi.org/10.1007/ s11947-014-1274-1

How to cite this article: Onwude, D. I., Iranshahi, K., Martynenko, A., \& Defraeye, T. Electrohydrodynamic drying: Can we scale-up the technology to make dried fruits and vegetables more nutritious and appealing? Compr Rev Food Sci Food Saf. 202120:;5283-5313. https://doi.org/10.1111/1541-4337.12799. 